\title{
CORAIS COMO ORGANISMOS BIOMONITORES: APLICAÇÃO, PRÉ-TRATAMENTO E DETERMINAÇÃO DE ELEMENTOS MAJORITÁRIOS E MINORITÁRIOS
}

\author{
Gilmara F. Eça, Carlos V. S. Mendonça Filho e Vanessa Hatje* \\ Instituto de Química, Universidade Federal da Bahia, Rua Barão de Geremeoabo, s/n, Campus Universitário de Ondina, 40170-115 \\ Salvador - BA, Brasil / INCT de Energia e Ambiente \\ Wagna P. C. Santos \\ Instituto Federal de Educação, Ciência e Tecnologia da Bahia, Rua Emídio dos Santos, s/n, Campus Salvador, 40301-015 Salvador \\ - BA, Brasil
}

Recebido em 13/5/11; aceito em 3/10/11; publicado na web em 4/1/12

\begin{abstract}
CORALS AS BIOMONITORS: APPLICATION, PRE-TREATMENT AND DETERMINATION OF MAJOR AND TRACE ELEMENTS. Corals incorporate major and trace elements in their tissues and skeletons, acting as good proxies for contaminant inputs over time. This incorporation occurs by a variety of mechanisms and depends on the bioavailability of elements. Corals are very susceptible to metal contamination during sample collection. As such, pre-treatment procedures need to include a decontamination step. The high $\mathrm{Na}$ and $\mathrm{Ca}$ concentrations in the matrix make the determination of trace metals an analytical challenge. The present paper reviews all the information published on coral sample pretreatments, metal determinations in corals, and also discusses the use of coral to monitor metal contamination.
\end{abstract}

Keywords: monitoring; contamination; $\mathrm{CaCO}_{3}$ matrix.

\section{INTRODUÇÃOO}

No ambiente aquático, elementos presentes em nível traço e em concentrações maiores podem ocorrer na fração dissolvida, coloidal, associados ao sedimento (material particulado e de fundo) e também aos tecidos biológicos. Os metais, em especial $\mathrm{Cd}, \mathrm{Pb}$ e $\mathrm{Hg}$, afetam a biota marinha, tanto pela mobilização das espécies metálicas, da fração particulada para a dissolvida, seguida pela assimilação da fase aquosa, como por meio da ingestão de sedimentos pela macrofauna bentônica, seguida da assimilação dos metais pelos intestinos. ${ }^{1}$

Os íons metálicos ocorrem nas formas livres, como complexos simples, com ligantes inorgânicos, quelatos, e ligantes orgânicos multidentados, adsorvidos na superfície de partículas. Os ligantes orgânicos podem ocorrer naturalmente, na forma de macromoléculas (e. g. proteínas, polissacarídeos, lipídios, lignina), contendo muitos sítios de ligação, ou como moléculas pequenas de origem antropogênica (e. g. cianetos, fluoretos, amônia). ${ }^{2}$ Os íons metálicos ligam-se à matéria orgânica, através do processo de quelação, formando complexos ou compostos de coordenação, que, eventualmente, se precipitam para o sedimento de fundo, afetando a biodisponibilidade dos elementos majoritários e minoritários. Os sedimentos de fundo são um depósito importante de contaminantes, não apenas de metais, mas também de contaminantes orgânicos, como os hidrocarbonetos policíclicos aromáticos. A ressuspensão de sedimentos de fundo contaminados pode contribuir para o aumento da biodisponibilidade de contaminantes para os organismos aquáticos, ${ }^{3}$ atuando como fonte de contaminantes para a coluna d'água.

A biodisponibilidade de espécies metálicas, numa perspectiva ambiental, pode ser definida como a concentração de metais livres e disponíveis na água ou associada aos sedimentos, sendo passíveis de incorporação, ao longo do tempo, aos tecidos dos organismos, por todas as vias, e podendo bioacumular e causar efeitos tóxicos. A bioacumulação, por sua vez, é o acúmulo líquido de um ou mais elementos-traço nos tecidos de um organismo, como resultado do

*e-mail: vhatje@ufba.br consumo de todas as rotas ou fontes disponíveis de alimento (e. g. água, sedimento etc.). Os padrões de bioacumulação podem diferir amplamente, de elemento para elemento, e entre diferentes organismos. A bioacumulação pode ser fortemente afetada pelas condições ambientais (e. g. química da água, do sedimento) ou por tipos de alimentos acessíveis ao organismo. ${ }^{4}$ Além disso, a bioacumulação de elementos-traço nos organismos depende de outros fatores, tais como fontes de contaminação, especiação química dos contaminantes, aspectos fisiológicos, ${ }^{5,6}$ estágios de vida (larval, maduro, estágio reprodutivo) e longevidade dos organismos.

A biodisponibilidade e, por sua vez, a bioacumulação são afetadas pelas características do sedimento, tais como concentração de sulfetos voláteis, óxidos de manganês, ferro e alumínio, $\mathrm{pH}, \mathrm{Eh},{ }^{7}$ granulometria e matéria orgânica. ${ }^{3}$ A determinação quantitativa da biodisponibilidade de contaminantes para os organismos tem sido amplamente utilizada em programas de monitoramento ambiental no meio aquático., ${ }^{48-10}$

Vários grupos faunísticos são utilizados como biomonitores da qualidade ambiental, tais como os crustáceos, peixes, corais e, principalmente, os macroinvertebrados bentônicos (e. g. bivalves). Os biomonitores geralmente são organismos sedentários, abundantes, tolerantes à contaminação ambiental, cosmopolitas; possuem tempo de vida longo e são fáceis de identificar e amostrar. ${ }^{11}$ Eles respondem simultaneamente a diferentes agentes estressantes, refletindo, deste modo, o nível de degradação do ecossistema. Ao longo de um gradiente de contaminação, os grupos mais resistentes podem se tornar dominantes e os grupos mais sensíveis podem se tornar raros ou mesmo desaparecerem. ${ }^{12}$

A acumulação de elementos-traço nos biomonitores varia de forma intraespecífica (entre indivíduos da mesma espécie ou, ainda, em um mesmo organismo) e interespecífica (entre diferentes espécies, do mesmo grupo ou não). No caso específico dos corais construtores de recifes (hermatípicos), a acumulação ocorre no tecido mole e no exoesqueleto calcário, de maneira diferenciada. Um aspecto importante, em relação ao uso de corais hermatípicos como biomonitores, é que várias espécies habitam o ecossistema recifal e estão sujeitas às mesmas forçantes ambientais, i.e. padrão de circulação, salinidade, concentração 
de material particulado em suspensão, temperatura e luz (i. e. na mesma profundidade). Cada uma destas espécies apresenta taxa de crescimento diferenciada, possivelmente, interferindo no padrão e na quantidade de cada contaminante acumulado no tecido e também no esqueleto do coral. Assim, a relação causa-efeito entre organismos e contaminantes será diferenciada, não só entre as espécies de corais, entre o tecido vivo e o esqueleto, mas também entre elementos químicos. Adicionalmente, o estudo simultâneo de várias espécies de corais permite a comparação das vias de acumulação, do efeito dos contaminantes na fisiologia e no padrão de bioacumulação de cada espécie. Porém, ainda se trata de uma hipótese a ser testada. Outra vantagem da utilização de corais hermatípicos como organismos biomonitores está nas respostas destes organismos às mudanças climáticas (e. g. aumento de temperatura e acidificação dos oceanos), as quais causam branqueamento e fragilização das colônias coralíneas. A influência destas mudanças no padrão de acumulação de elementos nos tecidos e no esqueleto, entretanto, ainda é desconhecida. Assim, as particularidades da ecologia de corais e suas relações com as mudanças climáticas (e. g. salinidade, $\mathrm{pH}$ e temperatura dos oceanos) tornam esta espécie uma ferramenta importante, não apenas para estudos de contaminação ambiental, mas também para estudos de alterações globais e suas influências nos ecossistemas costeiros. Assim, o uso deste biomonitor pode subsidiar a avaliação de mudanças e de impactos de pequena escala temporal, mas também de longa escala, visto que a estrutura calcária dos corais "documenta" processos e mudanças ambientais, ao longo de décadas ou mesmo centenas de anos. Estudos com outros organismos biomonitores (e. g. poliquetas e ostras) não registram variações de contaminantes, ao longo do tempo, como no caso do registro ambiental observado ao longo do eixo vertical de crescimento das colônias de corais. Complementarmente aos estudos de contaminação em esqueletos de corais, os estudos de esclerocronologia e datação permitem correlacionar eventos específicos no tempo (e. g. instalação de um empreendimento) às concentrações de elementos majoritários e minoritários no esqueleto coralíneo.

A utilização simultânea de outros grupos de organismos, além dos corais, é vantajosa e pode gerar importantes resultados sobre o efeito de contaminantes em diferentes níveis tróficos do ecossistema. ${ }^{4}$ Adicionalmente, como os métodos de incorporação de contaminantes são diferentes para cada grupo de organismos, o uso simultâneo de várias espécies permite uma maior generalização dos resultados. Em virtude das particularidades dos organismos biomonitores, a escolha da(s) espécie(s) a ser(em) utilizada(s) deve ser feita de maneira cuidadosa, considerando-se as características químicas, físicas, biológicas e antrópicas de cada ambiente a ser estudado, bem como a ocorrência das espécies biomonitoras.

Embora a utilização de organismos biomonitores seja antiga, existem potenciais grupos de organismos monitores, como os corais, que ainda não foram devidamente explorados, criando-se uma grande oportunidade para testar modelos e hipóteses sobre os clássicos problemas de incorporação e biodisponibilidade de contaminantes, bem como de mudanças climáticas. Este trabalho tem por objetivo apresentar uma revisão dos procedimentos mais usados nas etapas de pré-tratamento, digestão e determinação de elementos majoritários e minoritários em esqueletos de corais e, assim, avaliar a importância do uso de corais como biomonitores. Neste estudo, recomenda-se o uso de metodologias mais consistentes, tanto do ponto de vista analítico, como de desenhos experimentais, compatíveis com a biologia e a ecologia de corais, subsidiando assim o potencial de corais como biomonitores.

\section{OS CORAIS E A INCORPORAÇÃO DE ELEMENTOS MAJORITÁRIOS E MINORITÁRIOS}

Os recifes de corais são bioconstruções formadas por esqueletos calcários, corais e algas, acumulados ao longo do tempo. Os corais responsáveis pela formação dos recifes são os chamados corais pétreos ou escleractínios, que vivem em simbiose com as zooxantelas, um tipo de microalga. Estas microalgas fornecem grande parte do carbono consumido pelos corais (i. e. glicerol, glicose e alanina). Além disso, as algas simbiontes aumentam a capacidade dos corais de sintetizar o carbonato de cálcio $\left(\mathrm{CaCO}_{3}\right)$, que é utilizado para formar o seu esqueleto. ${ }^{13}$

Os recifes de corais estão entre os mais diversos, complexos e produtivos, ecossistemas do planeta. Sua estrutura tridimensional abriga uma infinidade de organismos (peixes, moluscos, gastrópodes, poliquetas, esponjas etc.), sendo de extrema importância em termos de recursos biológicos..$^{14,15}$

Os corais secretam estruturas constituídas por $\mathrm{CaCO}_{3}$ abaixo da camada dos tecidos vivos (pólipos). Os pólipos absorvem $\mathrm{CaCO}_{3}$ da água do mar e o transferem, por difusão e bombeamento, para o local de calcificação, localizado na matriz esquelética. Nos corais, a calcificação e a fotossíntese são influenciadas pela química do carbonato, a temperatura da água e a luz solar. ${ }^{14,16}$

O cálcio e o carbono inorgânico dissolvido (CID) são os dois maiores substratos de fotossíntese e calcificação. O CID distribui-se na água, sob três formas em equilíbrio: dióxido de carbono $\left(\mathrm{CO}_{2}\right)$, bicarbonato $\left(\mathrm{HCO}_{3}^{-}\right)$e carbonato $\left(\mathrm{CO}_{3}^{2-}\right)$ :

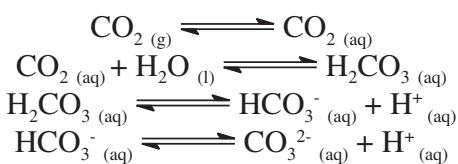

O equilíbrio das formas de CID na água depende de fatores como temperatura, pressão, consumo e produção dos organismos. ${ }^{17}$

Além do cálcio, contaminantes e sedimentos podem ser incorporados à estrutura carbonácea dos corais ${ }^{18}$ durante o crescimento das colônias, nos esqueletos e em zooxantelas associadas aos pólipos. ${ }^{19}$

A incorporação de íons metálicos aos corais (Figura 1) ocorre tanto por meio da fração dissolvida, como da fração particulada (micro-organismos, material particulado em suspensão, detritos). ${ }^{20,21}$ A ressuspensão de sedimentos de fundo, devido à ação de ventos, bioturbação e marés, também pode ser um mecanismo importante de biodisponibilização, seguida de potencial incorporação de contaminantes pelos recifes de corais. ${ }^{22} \mathrm{~A}$ incorporação de íons metálicos no esqueleto do coral pode ocorrer por meio da substituição do cálcio, da associação com a matéria orgânica dentro do esqueleto, da retenção de material particulado nas cavidades do esqueleto, da alimentação ou, ainda, pela adsorção à superfície esquelética. ${ }^{14,16,18,23,24} \mathrm{~A}$ principal forma de incorporação do metal (Me) no esqueleto dos corais ocorre por troca iônica, de acordo com a seguinte reação geral:

$$
\mathrm{CaCO}_{3}(\mathrm{~s})+\mathrm{Me}^{2+}(\mathrm{aq}) \rightleftharpoons \mathrm{MeCO}_{3}(\mathrm{~s})+\mathrm{Ca}^{2+}(\mathrm{aq})
$$

Os íons metálicos divalentes, que têm compatibilidade para a substituição do $\mathrm{Ca}^{2+}$ nos sítios da aragonita, são o $\mathrm{Fe}, \mathrm{Sn}, \mathrm{Eu}, \mathrm{Sr}$ e Ba. Os íons divalentes de $\mathrm{Fe}$ e $\mathrm{Sn}$ apresentam raio iônico menor que o íon $\mathrm{Ca}^{2+}$ (raio = 0,99 Ângstron) e tendem a formar calcita, enquanto que íons de raio iônico maior ( $\mathrm{Eu}, \mathrm{Sr}$ e $\mathrm{Ba}$ ) formam a aragonita. A incorporação de metais como $\mathrm{Mn}, \mathrm{Cd}, \mathrm{Co}, \mathrm{Ni}$ e $\mathrm{Pb}$ na estrutura carbonática varia de acordo com o tamanho do raio iônico divalente. Os íons metálicos divalentes de $\mathrm{Mn}, \mathrm{Cd}$ e $\mathrm{Ni}$, por exemplo, possuem raio $<0,99 \AA$ (raio iônico do $\mathrm{Ca}^{2+}$ ), substituindo o $\mathrm{Ca}^{2+}$ no esqueleto para formar a estrutura da calcita. Já o íon $\mathrm{Pb}^{2+}$ possui raio $>0,99 \AA \mathrm{e}<1,40 \AA$, substituindo o $\mathrm{Ca}^{2+}$ para formar aragonita. Esta substituição pode não ocorrer com os íons divalentes do Co e Ra, por exemplo, pois estes possuem raio iônico > 1,40 ̊ e não formam estrutura carbonática. ${ }^{20}$ 


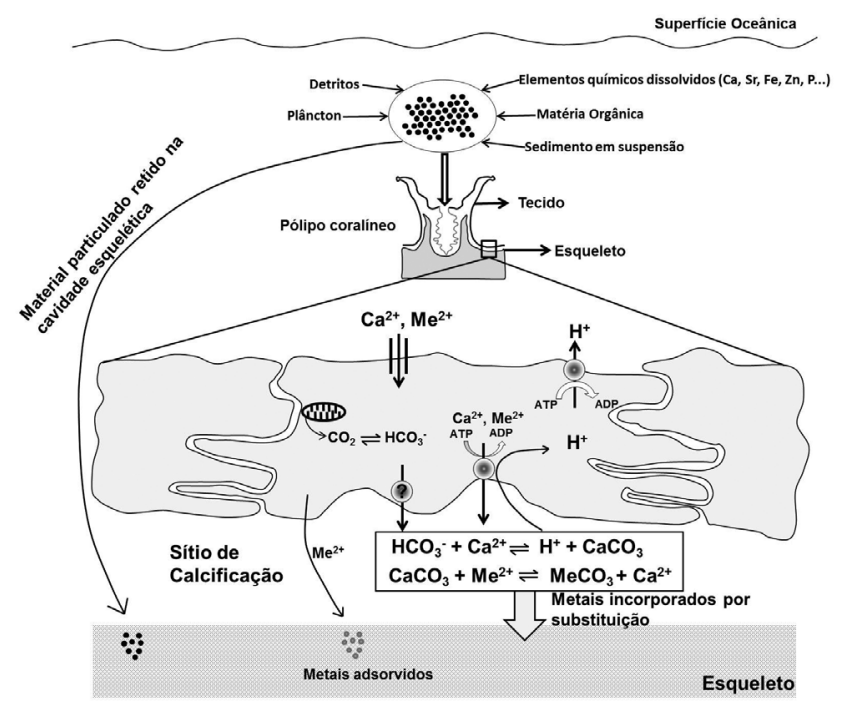

Figura 1. Mecanismos de incorporação de contaminantes nas colônias de corais

As concentrações de elementos-traço nos corais variam entre os tecidos e esqueletos, bem como entre as espécies de corais. Considerando as espécies Montipora digitata, Porites andrewsi, Lobophyllia corymbosa, Acropora formosa e Psammocora contigua, amostradas por Anu e colaboradores, ${ }^{25}$ esta última apresentou maiores concentrações de $\mathrm{Mn}, \mathrm{Cd}, \mathrm{Co}, \mathrm{Zn}, \mathrm{Cu}, \mathrm{Cr}, \mathrm{Ni}$ e $\mathrm{Pb}$ nos tecidos, enquanto as outras quatro exibiram maiores concentrações de $\mathrm{Mn}$, $\mathrm{Cd}, \mathrm{Co}, \mathrm{Ni}$ e $\mathrm{Pb}$ nos esqueletos (Tabela 1 ).

Os esqueletos (aragonita) dos corais incorporam também ametais, como o fósforo $(\mathrm{P})$, presente em compostos inorgânicos, por meio de substituição aniônica, onde o carbonato $\left(\mathrm{CO}_{3}{ }^{2-}\right)$ da aragonita é substituído pelo monoidrogenofosfato $\left(\mathrm{HPO}_{4}^{2-}\right)$. A forma orgânica de $\mathrm{P}$ também pode ser incorporada ao esqueleto do coral, de várias formas: material orgânico intracristalino incorporado durante a precipitação; adsorção de $\mathrm{P}$ orgânico dissolvido e, por meio de algas endolíticas, fungos ou bactérias. A razão P/Ca no esqueleto do coral pode ser usada para estudar mudanças ocorridas no nível de nutrientes da água, ao longo do tempo. ${ }^{26}$

Por sua vez, os tecidos biológicos dos corais, associados às zooxantelas, podem apresentar concentrações mais elevadas de elementos como $\mathrm{Fe}$ e $\mathrm{Zn}$, do que os esqueletos, pois estes participam de processos metabólicos ligados às metaloenzimas. ${ }^{27}$

A maioria dos trabalhos que têm determinado a concentração de elementos majoritários e minoritários em corais utiliza como matriz o esqueleto desses animais. $\mathrm{O}$ esqueleto dos corais é uma fonte de informações importantes sobre as mudanças ocorridas no ambiente, incluindo variações, ao longo do tempo, na composição química dos oceanos. ${ }^{15}$

A razão $\mathrm{Me} / \mathrm{Ca}$ varia em função da concentração de metal incorporada ao esqueleto. Razões como Cd/Ca e Mn/Ca em matrizes esqueléticas, por exemplo, servem para detectar mudanças nas condições de temperatura e de salinidade, devido às variações nos aportes fluviais, eventos de ressurgência, entre outros. ${ }^{28-30} \mathrm{~A}$ razão $\mathrm{Si} / \mathrm{Ca}$ pode ser mais alta, no esqueleto dos corais de recifes costeiros, do que nos de áreas distantes da costa. Isto se deve à proximidade dos recifes costeiros com as fontes de silício, provenientes dos ambientes continentais. ${ }^{31}$

Elementos como $\mathrm{Sr}$, Ca e Ba são constituintes naturais do esqueleto do coral, mas podem ser indicadores de variações nas condições do ambiente pelágico. ${ }^{32}$ Medidas da razão $\mathrm{Sr} / \mathrm{Ca}$ e de isótopo de oxigênio $\left(\delta^{18} \mathrm{O}\right)$ nos esqueletos são usadas para avaliar variações na temperatura anual da superfície do mar (TSM) ${ }^{30,33}$ Segundo Knutson e colaboradores ${ }^{14}$ e Fallon e colaboradores, ${ }^{34}$ a razão $\mathrm{Sr} / \mathrm{Ca}$ e sua relação com o $\delta^{18} \mathrm{O}$ depende da faixa de temperatura da água. Estes autores relataram que a razão $\mathrm{Sr} / \mathrm{Ca}$ em Porites lobata no Japão foi aproximadamente linear, em temperatura superior a $18{ }^{\circ} \mathrm{C}$, e não linear abaixo de $18{ }^{\circ} \mathrm{C}$.

Em regiões onde a variação de temperatura é pequena, como próximo ao Equador, anomalias térmicas na água podem afetar recifes, promovendo o branqueamento de espécies. Estudo realizado na costa baiana $^{35}$ mostrou que os recifes localizados próximo ao continente foram os mais afetados por anomalias térmicas da água (até $1^{\circ} \mathrm{C}$ por mais de duas semanas), apresentando ainda uma maior incidência de branqueamento. As espécies mais afetadas foram as mais abundantes: Mussismilia hispida, Siderastrea spp., Montastraea cavernosa, Agaricia agaricites e Porites.

Vale ressaltar que, independentemente do mecanismo de incorporação, os corais têm se mostrado como bons traçadores de mudanças de temperatura, salinidade e contaminantes no ambiente marinho. ${ }^{27,36-38}$

\section{Utilização de corais como organismos biomonitores}

Os corais têm sido bastante usados como biomonitores de contaminação por metais e ametais, hidrocarbonetos de petróleo e outros compostos orgânicos. ${ }^{14-16,23,30,31,39-42}$ Seu emprego se iniciou após a descoberta de bandas de densidade esclerocronológicas, reveladas por raios-X de esqueletos de corais. Esta descoberta permitiu a obtenção de informações sobre o crescimento dos corais e de variações nas condições do ambiente marinho, ao longo do tempo. Os níveis de contaminantes na matriz carbonática dos corais são registrados nos anéis de crescimento desses animais. Dessa forma, é interessante fazer a datação do exoesqueleto, antes da determinação química, para a obtenção do tempo de vida do organismo, a identificação de episódios específicos, ao longo do tempo, e o estabelecimento de teores de contaminantes para cada período de crescimento. ${ }^{14,15,30}$

Pesquisas realizadas nos anos 80 mostraram a acumulação de $\mathrm{Pb}$, ao longo de décadas, registrada em bandas de corais coletados no Oeste do Atlântico Norte, na Flórida, no Pacífico e no Oceano Índico, em consequência da Revolução Industrial. ${ }^{43} \mathrm{Na}$ década de 1990, pesquisa realizada por Hanna e Muir ${ }^{32}$ mostrou que as espécies Porites lutea, Goniastrea retiformis e Pocillopora verrucosa, de áreas contaminadas da Arábia Saudita, apresentaram concentrações de metais e ametais $(\mathrm{Cu}, \mathrm{Zn}, \mathrm{Pb}, \mathrm{Mn}, \mathrm{Fe}, \mathrm{Ni}, \mathrm{Cd}, \mathrm{V}, \mathrm{Al}, \mathrm{Cr}, \mathrm{Mg}, \mathrm{B}, \mathrm{Ca}$ e $\mathrm{Sr}$ ) mais elevadas do que em espécies de áreas não contaminadas.

Trabalhos feitos ainda na década de 1980, em regiões do Kuwait e da Arábia Saudita, revelaram a contaminação de corais por derivados de petróleo. ${ }^{41}$ Os próprios hidrocarbonetos de petróleo são também fontes de metais-traço (e. g. Ni e V) ${ }^{44}$ A longo prazo, a incorporação do $\mathrm{V}$ no esqueleto de corais afeta o crescimento, a diversidade e pode causar a morte desses animais. ${ }^{40}$

O aumento do nível de contaminação nas águas marinhas pode provocar mudanças substanciais em recifes de corais. Entre as formas de impacto negativo, devido à ocorrência de concentração elevada de metais, destacam-se: i. estresse fisiológico; ${ }^{20}$ ii. inibição da fertilização de corais $;{ }^{45,46}$ iii. mudança na população de zooxantelas ${ }^{47}$ mudança na taxa de fotossíntese ${ }^{48}$ e aumento da mortalidade de corais. ${ }^{49}$

A exposição de corais a íons metálicos tóxicos também pode levar ao branqueamento. No entanto, este processo varia com a espécie do coral e o tipo de metal incorporado. ${ }^{9}$ As concentrações de metais encontradas em tecidos e esqueletos de corais diferem bastante entre as espécies e regiões estudadas (Tabela 1). Para os metais-traço ( $\mathrm{Zn}, \mathrm{Cu}, \mathrm{Cr}, \mathrm{Ni}$ e $\mathrm{Pb}$ ), avaliados em uma mesma região da Austrália, Goniastrea aspera ${ }^{50,51}$ exibiu muito mais $\mathrm{Zn}$ em seu esqueleto do que Pocillopora damicornis..$^{22,50}$ No mar arábico, Montipora digitata 
Tabela 1. Concentrações de elementos majoritários e minoritários em esqueletos de corais. Média \pm desvio-padrão ou concentração mínima e máxima. ND = não detectado

\begin{tabular}{|c|c|c|c|c|c|c|c|c|c|c|c|c|c|c|c|c|}
\hline \multirow{2}{*}{ Local } & \multirow{2}{*}{ Espécie } & \multicolumn{14}{|c|}{ Concentração $\left(\mu \mathrm{g} \mathrm{g}^{-1}\right)$} & \multirow[b]{2}{*}{ Ref } \\
\hline & & $\mathrm{Ba}$ & $\mathrm{Sr}$ & $\mathrm{Fe}$ & $\mathrm{Mn}$ & As & $\mathrm{Al}$ & $\mathrm{Hg}$ & $\mathrm{Cd}$ & $\mathrm{Co}$ & $\mathrm{Zn}$ & $\mathrm{Cu}$ & $\mathrm{Cr}$ & $\mathrm{Ni}$ & $\mathrm{Pb}$ & \\
\hline \multirow{2}{*}{ Costa do Brasil } & $\begin{array}{l}\text { Meandrina } \\
\text { braziliensis }\end{array}$ & 85 & 0,87 & $<5$ & $<2$ & - & - & - & - & 0,06 & 2 & 8 & $<1$ & $<2$ & $<2$ & \multirow{11}{*}{31} \\
\hline & $\begin{array}{l}\text { Madracis sp. cf. M. } \\
\text { pharensis }\end{array}$ & 38 & 0,85 & 10 & 4 & - & - & - & - & 0,08 & 2 & $<2$ & 23 & - & - & \\
\hline Baía da Flórida & Meandrina areolata & 32 & & 30 & $<5$ & - & - & - & - & 0,04 & 2 & 1 & $<1$ & $<2$ & $<2$ & \\
\hline Florida Keys & Porites porites & 15 & 0,83 & 45 & 4 & - & - & - & - & 2 & $<2$ & 2 & $<2$ & $<2$ & $<2$ & \\
\hline \multirow{3}{*}{ Baía Discovery } & Madracis mirabilis & 11 & 0,86 & $<5$ & $<2$ & - & - & - & - & 0,06 & $<2$ & $<2$ & 14 & 2 & $<2$ & \\
\hline & Montastrea annularis & 10 & 0,80 & 5 & $<2$ & - & - & - & - & 0,06 & $<2$ & 2 & 10 & 3 & $<2$ & \\
\hline & Scolmia cubensis & 9 & 0,75 & 13 & 3 & - & - & - & - & 0,06 & $<2$ & $<2$ & 2 & 3 & $<2$ & \\
\hline \multirow{4}{*}{$\begin{array}{l}\text { Police Pool Wharf, } \\
\text { Kingston Harbor }\end{array}$} & Madracis mirabilis & 24 & 0,86 & 95 & 9 & - & - & - & - & 0,17 & $<2$ & 5 & 0,2 & $<2$ & $<2$ & \\
\hline & Montastrea annularis & 25 & 0,75 & 20 & 5 & - & - & - & - & 0,12 & $<2$ & 11 & $<2$ & $<2$ & $<2$ & \\
\hline & Scolmia cubensis & 43 & 0,75 & 880 & - & - & - & - & - & 0,47 & 3 & 16 & 5 & 3 & 3 & \\
\hline & Phyllangia americana & 27 & 0,77 & 290 & - & - & - & - & - & $<2$ & 7 & 20 & $<2$ & 2 & 4 & \\
\hline Ilhas Virgens & Montastrea annularis & - & - & - & - & - & - & - & - & - & - & - & - & - & $\begin{array}{c}0,09- \\
0,40\end{array}$ & 55 \\
\hline Costa do Caribe & Siderastrea siderea & - & - & 113 & 91,6 & - & - & - & 7,5 & - & 10,2 & 2,0 & - & - & 31,0 & 63 \\
\hline \multirow{5}{*}{ Recife de Havana } & Colpophyllia Natans & - & - & 13,7 & 0,97 & - & - & - & - & - & - & 5,73 & - & 0,37 & - & \multirow{5}{*}{67} \\
\hline & $\begin{array}{l}\text { Mycetophillia } \\
\text { lamarckiana }\end{array}$ & - & - & 50,5 & 1,74 & - & 390 & - & - & 0.1 & - & 1,05 & 12,3 & 0,56 & - & \\
\hline & Porites porites & - & - & 60,9 & 5,37 & - & 296 & - & - & - & - & 1,05 & 17,5 & 1,20 & - & \\
\hline & Dichocoemia stokesi & - & - & 60,1 & 8,32 & - & 848 & - & - & 0,07 & - & 2,12 & 46,5 & 0,52 & - & \\
\hline & Porites astreoides & - & - & 58,9 & 2,46 & - & 923 & - & - & 0,42 & - & 1,42 & 13,7 & 2,18 & - & \\
\hline Recife Davies & Porites mayeri & $\begin{array}{c}3,51 \pm \\
0,04\end{array}$ & $\begin{array}{c}7463 \pm \\
0,7\end{array}$ & - & - & - & - & - & - & - & - & - & - & - & - & \multirow{2}{*}{42} \\
\hline $\begin{array}{l}\text { Recife de Punta } \\
\text { Brava }\end{array}$ & Porites astreoides & - & - & $\begin{array}{c}62,0 \pm \\
11,0\end{array}$ & - & - & $\begin{array}{c}139 \pm \\
204\end{array}$ & $\begin{array}{c}0.39 \pm \\
0,07\end{array}$ & - & - & $\begin{array}{c}10,7 \pm \\
0,84\end{array}$ & $\begin{array}{c}16,3 \pm \\
1,56\end{array}$ & $\begin{array}{c}0,80 \pm \\
0,08\end{array}$ & - & $\begin{array}{c}0,21 \pm \\
0,06\end{array}$ & \\
\hline $\begin{array}{l}\text { Recife de Bajo } \\
\text { Caimán }\end{array}$ & Porites astreoides & - & - & $\begin{array}{c}18,1 \pm \\
2,34\end{array}$ & - & - & $\begin{array}{c}13,9 \pm \\
2,37\end{array}$ & $\begin{array}{c}0,42 \pm \\
0,11\end{array}$ & - & - & $\begin{array}{c}9,12 \pm \\
0,71\end{array}$ & $\begin{array}{c}12,5 \pm \\
0,84\end{array}$ & $\begin{array}{c}1,95 \pm \\
0,57\end{array}$ & - & $\begin{array}{c}1,04 \pm \\
0,20\end{array}$ & 36 \\
\hline \multirow{2}{*}{ Heron Island } & Acropora nobilis & - & - & - & - & - & - & - & $<0,01$ & - & $\begin{array}{c}0,86 \pm \\
0,17 \\
\end{array}$ & $\begin{array}{c}0,32 \pm \\
0,15 \\
\end{array}$ & $<0,3$ & $\begin{array}{c}0,45 \pm \\
0,21 \\
\end{array}$ & $\begin{array}{c} \pm 0,09 \pm \\
0,04 \\
\end{array}$ & \multirow{2}{*}{50} \\
\hline & Goniastrea aspera & - & - & - & - & - & - & - & $<0,01$ & - & $\begin{array}{c}1,87 \pm \\
0,75 \\
\end{array}$ & $\begin{array}{c}0,23 \pm \\
0,10 \\
\end{array}$ & $<0,3$ & $\begin{array}{c}1,62 \pm \\
0,75 \\
\end{array}$ & $\begin{array}{c} \pm 0,04 \pm \\
0,01 \\
\end{array}$ & \\
\hline Baía Pioneer & Goniastrea aspera & - & - & - & - & - & - & - & $<0,09$ & - & $\leq 28$ & $\begin{array}{c}3,0 \pm \\
0,8\end{array}$ & $\leq 29$ & $34 \pm 7$ & $\begin{array}{c}0,33 \pm \\
0,14\end{array}$ & \multirow{5}{*}{51} \\
\hline \multirow{3}{*}{ Baía Nelly } & $\begin{array}{l}\text { Pocillopora } \\
\text { damicornis }\end{array}$ & - & - & - & - & - & - & - & $<0,09$ & - & $\leq 23$ & $\begin{array}{c}1,6 \pm \\
0,3\end{array}$ & $\begin{array}{c}44 \pm \\
33\end{array}$ & $\begin{array}{c}31 \pm \\
10\end{array}$ & $<0,24$ & \\
\hline & Acropora formosa & - & - & - & - & - & - & - & $\begin{array}{c}0,18 \pm \\
0,09 \\
\end{array}$ & - & $21 \pm 8$ & $\begin{array}{c}1,9 \pm \\
0,6 \\
\end{array}$ & $\begin{array}{c}67 \pm \\
21 \\
\end{array}$ & $\leq 4,24$ & $4 \leq 0,24$ & \\
\hline & $\begin{array}{l}\text { Pocillopora } \\
\text { damicornis }\end{array}$ & - & - & - & - & - & - & - & $<0,09$ & - & $37 \pm 8$ & $\begin{array}{c}5,5 \pm \\
1,6\end{array}$ & $\leq 21$ & $10 \pm 7$ & $\begin{array}{c}70,19 \pm \\
0,10\end{array}$ & \\
\hline Porto Townsville & Goniastrea aspera & - & - & - & - & - & - & - & $\begin{array}{c}0,09 \pm \\
0,09 \\
\end{array}$ & - & $\begin{array}{c}447 \pm \\
112 \\
\end{array}$ & $14 \pm 4$ & $\begin{array}{c}31 \pm \\
21 \\
\end{array}$ & $\begin{array}{c}32 \pm \\
15 \\
\end{array}$ & $\begin{array}{c}8,2 \pm \\
1,7\end{array}$ & \\
\hline Costa do Panamá & Siderastrea siderea & - & - & - & - & - & - & $\begin{array}{c}21,4 \pm \\
12,5 \\
\end{array}$ & - & - & - & - & - & - & - & \multirow{2}{*}{56} \\
\hline Costa Rica & Siderastrea siderea & - & - & - & - & - & - & $\begin{array}{c}15,2 \pm \\
6,6\end{array}$ & - & - & - & - & - & - & - & \\
\hline Recife Caganhão & Porites lobata & - & - & $0,5-3,3$ & 0,8 & - & - & - & - & - & 1,0 & 0,7 & - & - & - & \multirow{2}{*}{58} \\
\hline Recife Ulan & Porites lobata & - & - & - & 1,0 & - & - & - & - & - & 1,8 & 3,1 & - & - & - & \\
\hline $\begin{array}{l}\text { Costa Egípcia do } \\
\text { Mar Vermelho }\end{array}$ & Acropora sp. & - & - & 127 & - & - & - & 0,81 & 1,31 & - & 6,47 & 7,58 & - & - & 5,56 & 52 \\
\hline Ilha Magnética & Acropora tenuis & $\begin{array}{c}55 \pm \\
16\end{array}$ & - & 16,3 & 0,09 & $<0,001$ & $<42$ & - & 0,001 & - & 0,5 & 0,001 & - & 0,7 & 0,05 & \multirow{2}{*}{19} \\
\hline Ilha One Tree & Acropora tenuis & $\begin{array}{c}64 \pm \\
21\end{array}$ & - & ND & 0,01 & $<0,001$ & $<28$ & - & $<0,001$ & - & 0,2 & 0,08 & - & 0,3 & 0,01 & \\
\hline Baía Nelly & $\begin{array}{l}\text { Pocillopora } \\
\text { damicornis }\end{array}$ & - & $\begin{array}{c}6824 \pm \\
62 \\
\end{array}$ & - & - & - & - & - & - & - & $\begin{array}{c}2,05 \pm \\
0,02 \\
\end{array}$ & $\begin{array}{c}0,04 \pm \\
0,05\end{array}$ & - & - & - & 22 \\
\hline Golfo de Aqaba & Porites & - & _. & $\begin{array}{c}14,5 \pm \\
2,42\end{array}$ & $\begin{array}{c}0,35 \pm \\
0,00\end{array}$ & - & - & _. & $\begin{array}{c}4,19 \pm \\
0,51\end{array}$ & - & $\begin{array}{c}7,32 \pm \\
0,67\end{array}$ & $\begin{array}{c}3,88 \pm \\
0,22\end{array}$ & - & - & $\begin{array}{c}38,2 \pm \\
3,24\end{array}$ & 27 \\
\hline
\end{tabular}


Tabela 1. continuação

\begin{tabular}{|c|c|c|c|c|c|c|c|c|c|c|c|c|c|c|c|c|}
\hline \multirow{2}{*}{ Local } & \multirow{2}{*}{ Espécie } & \multicolumn{14}{|c|}{ Concentração $\left(\mu \mathrm{g} \mathrm{g}^{-1}\right)$} & \multirow[b]{2}{*}{ Ref. } \\
\hline & & $\mathrm{Ba}$ & $\mathrm{Sr}$ & $\mathrm{Fe}$ & $\mathrm{Mn}$ & As & $\mathrm{Al}$ & $\mathrm{Hg}$ & $\mathrm{Cd}$ & Co & $\mathrm{Zn}$ & $\mathrm{Cu}$ & $\mathrm{Cr}$ & $\mathrm{Ni}$ & $\mathrm{Pb}$ & \\
\hline \multirow{5}{*}{$\begin{array}{l}\text { Arquipélago } \\
\text { Lakshadwee, } \\
\text { Mar Arábico }\end{array}$} & Montipora digitata & - & - & $\begin{array}{c}11,4 \pm \\
0,79\end{array}$ & $\begin{array}{c}2,47 \pm \\
0,21\end{array}$ & - & - & - & $\begin{array}{c}1,30 \pm \\
0,11\end{array}$ & $\begin{array}{c}4,76 \pm \\
0,26\end{array}$ & $\begin{array}{c}1,24 \pm \\
0,14\end{array}$ & $\begin{array}{c}1,87 \pm \\
0,11\end{array}$ & $\begin{array}{c}4,75 \pm \\
0,29\end{array}$ & $\begin{array}{c}5,80 \pm \\
0,39\end{array}$ & $\begin{array}{c}13,0 \pm \\
0,98\end{array}$ & \multirow{5}{*}{25} \\
\hline & Porites andrewsi & - & - & $\begin{array}{c}5,15 \pm \\
0,49 \\
\end{array}$ & $\begin{array}{c}2,74 \pm \\
0,18 \\
\end{array}$ & - & - & - & $\begin{array}{c}2,13 \pm \\
0,16\end{array}$ & $\begin{array}{c}7,30 \pm \\
0,57 \\
\end{array}$ & $\begin{array}{c}2,62 \pm \\
0,21 \\
\end{array}$ & $\begin{array}{c}0,49 \pm \\
0,06\end{array}$ & $\begin{array}{c}4,33 \pm \\
0,21\end{array}$ & $\begin{array}{c}11,1 \pm \\
0,89 \\
\end{array}$ & $\begin{array}{c}24,2 \pm \\
1,87 \\
\end{array}$ & \\
\hline & $\begin{array}{l}\text { Lobophyllia } \\
\text { corymbosa }\end{array}$ & - & - & $\begin{array}{c}12,8 \pm \\
0,89 \\
\end{array}$ & $\begin{array}{c}3,15 \pm \\
0,23\end{array}$ & - & - & - & $\begin{array}{c}2,55 \pm \\
0,19 \\
\end{array}$ & $\begin{array}{c}9,82 \pm \\
0,62\end{array}$ & $\begin{array}{c}2,23 \pm \\
0,19 \\
\end{array}$ & $\begin{array}{c}2,03 \pm \\
0,13\end{array}$ & $\begin{array}{c}5,44 \pm \\
0,38\end{array}$ & $\begin{array}{c}12,7 \pm \\
0,92 \\
\end{array}$ & $\begin{array}{c}26,4 \pm \\
1,98 \\
\end{array}$ & \\
\hline & Acropora formosa & - & - & $\begin{array}{c}0,53 \pm \\
0,14 \\
\end{array}$ & $\begin{array}{c}4,66 \pm \\
0,31 \\
\end{array}$ & - & - & - & $\begin{array}{c}2,53 \pm \\
0,19 \\
\end{array}$ & $\begin{array}{c}3,90 \pm \\
0,19\end{array}$ & $\begin{array}{c}2,04 \pm \\
0,13\end{array}$ & $\begin{array}{c}1,88 \pm \\
0,12\end{array}$ & $\begin{array}{c}2,34 \pm \\
0,21 \\
\end{array}$ & $\begin{array}{c}10,7 \pm \\
0,56\end{array}$ & $\begin{array}{c}23,8 \pm \\
1,82 \\
\end{array}$ & \\
\hline & $\begin{array}{l}\text { Psammocora } \\
\text { contigua }\end{array}$ & - & - & $\begin{array}{c}2,77 \pm \\
0,12 \\
\end{array}$ & $\begin{array}{c}0,32 \pm \\
0,03 \\
\end{array}$ & - & - & - & $\begin{array}{c}0,27 \pm \\
0,06 \\
\end{array}$ & $\begin{array}{c}0,79 \pm \\
0,08 \\
\end{array}$ & $\begin{array}{c}1,29 \pm \\
0,11 \\
\end{array}$ & $\begin{array}{c}1,02 \pm \\
0,09\end{array}$ & $\begin{array}{c}0,82 \pm \\
0,09 \\
\end{array}$ & $\begin{array}{c}2,07 \pm \\
0,11 \\
\end{array}$ & $\begin{array}{c}0,71 \pm \\
0,09\end{array}$ & \\
\hline Costa de Tuticorin & Acropora formosa & - & - & 42,1 & 5,36 & - & - & - & 4,53 & 4,30 & 3,14 & 2,46 & 2,58 & 72,3 & 25,6 & \multirow{3}{*}{37} \\
\hline Costa de Tuticorin & Porites andrewsi & - & - & 48,2 & 8,53 & - & - & - & 7,21 & 6,89 & 2,51 & 10,6 & 5,23 & 72,2 & 28,3 & \\
\hline Costa de Tuticorin & Montipora digitata & - & - & 74,3 & 15,2 & - & - & - & 3,25 & 7,21 & 2,35 & 2,56 & 16,4 & 96,5 & 46,1 & \\
\hline Golfo Triste & Siderastrea siderea & - & - & $\begin{array}{c}16,5 \pm \\
7,6 \\
\end{array}$ & - & - & $\begin{array}{c}504 \pm \\
439 \\
\end{array}$ & $\begin{array}{c}0,03 \pm \\
0,01 \\
\end{array}$ & - & - & - & - & - & - & - & \multirow{2}{*}{90} \\
\hline Golfo Triste & $\begin{array}{l}\text { Montastraea } \\
\text { faveolata }\end{array}$ & - & - & $\begin{array}{c}10,1 \pm \\
9,9\end{array}$ & - & - & - & $\begin{array}{c}206 \pm \\
220 \\
\end{array}$ & - & - & - & - & - & - & - & \\
\hline $\begin{array}{l}\text { Cayo Arcas, } \\
\text { Golfo do México }\end{array}$ & $\begin{array}{l}\text { Montastraea } \\
\text { annularis }\end{array}$ & 114 & 2000 & - & - & - & - & - & - & - & - & - & - & 14,0 & - & \multirow{2}{*}{44} \\
\hline $\begin{array}{l}\text { Triângulos, } \\
\text { Golfo do México }\end{array}$ & Montastraea annularis & 168 & 2000 & - & - & - & - & - & - & - & - & - & - & 18,3 & - & \\
\hline Golfo de Mannar & - & - & - & $\begin{array}{c}0,19 \\
-0,62 \\
0,38 \pm \\
0,11\end{array}$ & $\begin{array}{c}98,4- \\
138 \\
118 \pm \\
11,2\end{array}$ & $\begin{array}{c}6,71 \\
-15,6 \\
10,6 \pm \\
2,59\end{array}$ & - & - & $\begin{array}{c}0,28 \\
-1,31 \\
0,71 \pm \\
0,32\end{array}$ & $\begin{array}{c}0,56 \\
-5,29 \\
2,55 \pm \\
1,25\end{array}$ & $\begin{array}{c}44 \\
-135 \\
93,2 \pm \\
28,75\end{array}$ & - & $\begin{array}{c}7,25- \\
22,3 \\
13,8 \pm \\
3,86\end{array}$ & $\begin{array}{c}0,18 \\
-2,53 \\
0,86 \pm \\
0,59\end{array}$ & $\begin{array}{c}0,18- \\
4,56 \\
1,75 \pm \\
1,16\end{array}$ & 10 \\
\hline
\end{tabular}

apresentou maior concentração de $\mathrm{Pb}$ do que Porites. ${ }^{25}$ Isto mostra a capacidade diferenciada de cada espécie para acumular traços, ao longo do tempo, além da atuação de aspectos fisiológicos e tempos de vida dos espécimes envolvidos. Entre regiões diferentes amostradas, ${ }^{25,37,50,52}$ Acropora formosa foi a melhor biomonitora de Cr dentre as espécies. Para o $\mathrm{Pb}$, as espécies que se destacaram pelas maiores concentrações deste metal foram $M$. digitata, Porites e Lobophyllia corimbosa. ${ }^{25,27,37}$

Como mencionado acima, os níveis de íons metálicos nos esqueletos de corais diferem entre as espécies, assim como ocorre com outros organismos biomonitores. Estas variações na bioacumulação de elementos majoritários e minoritários ocorrem devido a diversos fatores: fontes e concentrações presentes na coluna d'água; biodisponibilidade dos elementos; aspectos fisiológicos; dieta alimentar e tempo de vida de cada espécie. Sugere-se, desse modo, que quanto maior for o tempo de vida de uma espécie e sua capacidade de incorporação, maior será o teor de elementos-traço incorporados aos esqueletos destes animais, ao longo do tempo. Quanto maior o nível de contaminação de uma região, maior a probabilidade de acumulação de contaminantes nos organismos.

Pesquisa realizada na Baía de Todos os Santos, na região nordeste do Brasil, mostrou que algumas espécies, tais como Porites branneri, Meandrina braziliensis, Stephanocoenia michelini e Millepora nítida, que eram abundantes em 1962, desapareceram, desde 2003, devido à baixa tolerância destas espécies ao aumento de turbidez ocorrido nesse ambiente..$^{53}$ Outros fatores, como o aumento do aporte de íons metálicos para esta região, também podem ter contribuído para o desaparecimento destas espécies. As espécies mais resistentes a condições estressantes observadas na Baía de Todos os Santos foram Montastrea cavernosa e Siderastrea stellata.$^{54}$ Como os corais obtêm seu alimento pela ingestão de material particulado e micro-organismos, sugere-se que as espécies de corais mais resistentes, nas condições estressantes da Baía de Todos os Santos, i. e. Montastrea cavernosa e Siderastrea stellata, sejam as melhores espécies biomonitoras no grupo dos corais, tanto para essa Baía, como ao longo da costa brasileira onde as mesmas ocorrem.

\section{PROCEDIMENTOS ANALÍTICOS}

\section{Coleta, procedimentos de descontaminação e preparo de amostras de corais}

Diferente de outros organismos biomonitores, como ostras e mariscos, a coleta, o preparo e a determinação de elementos majoritários e minoritários em amostras de coral é complexa. Amostras de corais são coletadas, geralmente, por um mergulhador autônomo. Dependendo do tamanho da colônia, são coletadas colônias inteiras ou são retirados testemunhos. A rotina de coleta de amostras inclui muitas etapas de manipulação, as quais são importantes fontes potenciais de contaminação. ${ }^{39}$ Isto se deve, em parte, às ferramentas utilizadas nas amostragens de corais, como, por exemplo, os testemunhadores e as serras pneumáticas, cujas lâminas são compostas por uma variedade de ligas metálicas. Assim, apesar do uso de medidas preventivas para se evitar a contaminação, a coleta e o pré-tratamento das amostras causa, potencialmente, a contaminação, especialmente por elementos como $\mathrm{Fe}, \mathrm{Zn}$ e Al, o que pode comprometer a análise ao nível de traço.

Após serem coletadas, as amostras são lavadas com água do local de coleta, guardadas em sacos plásticos e refrigeradas. Em laboratório, as espécies serão identificadas, lavadas com água deionizada e secas à temperatura ambiente, em um local previamente descontaminado e protegido de poeira (e. g. capela de fluxo laminar ou sala limpa). As amostras passam por várias etapas de limpeza, para remover a contaminação superficial, devido à coleta e secção das amostras. Na literatura mais antiga sobre corais, a descontaminação das amostras de esqueleto foi realizada com água deionizada e banho ultrassônico. ${ }^{31,34}$ Trabalhos posteriores mostraram a necessidade de se realizarem procedimentos mais completos de limpeza das amostras. 
Estes procedimentos incluíram etapas de lavagem, com ácidos diluídos, intercaladas com o uso de agentes oxidantes. ${ }^{21,22,39,40,55-59}$ Adicionalmente, deve-se considerar se o objetivo do estudo é determinar elementos-traço associados apenas à matriz carbonática do coral. Neste caso, deve-se, inicialmente, retirar todo o material orgânico do esqueleto, para não introduzir erros nas análises químicas, com a contabilização de elementos majoritários ou minoritários incorporados à fração orgânica dos tecidos (pólipos e algas simbiontes).

Para a remoção dos tecidos, podem ser utilizadas soluções oxidantes, em banho ultrassônico, que atuam na degradação da matéria orgânica. A mistura de peróxido de hidrogênio $\left(\mathrm{H}_{2} \mathrm{O}_{2}\right)$ e hidróxido de sódio $(\mathrm{NaOH})$ é a mais presente na literatura, sendo o $\mathrm{NaOH}$ usado para ajustar o pH da solução a 8,2 $22,25,37,39,44,50,60 \mathrm{e}$, assim, evitar a solubilização do material esquelético (Tabela 2). ${ }^{61} \mathrm{O} \mathrm{H}_{2} \mathrm{O}_{2}$ é adicionado geralmente às soluções ácidas, para evitar a formação de óxi-hidróxidos de $\mathrm{Fe}$ sob $\mathrm{pH}$ mais altos. ${ }^{62} \mathrm{O}$ Hipoclorito de sódio $(\mathrm{NaClO}) 5 \%$ é outro oxidante utilizado por alguns pesquisadores. ${ }^{58,63,64}$ Segundo Shen e Boyle, ${ }^{39}$ o pré-tratamento dos corais com o uso de oxidantes é fundamental para amostras com elevado conteúdo orgânico. Porém, para amostras que apresentem apenas inclusões detríticas, uma limpeza ácida é suficiente. Após a fase de oxidação, é feita a redução e a quelação da fase óxica, ou seja, a remoção dos óxidos formados na reação da matéria orgânica com a solução oxidante. Assim, observa-se o uso da mistura de hidrazina $\left(\mathrm{N}_{2} \mathrm{H}_{4}\right)$ e hidróxido de amônio $\left(\mathrm{NH}_{4} \mathrm{OH}\right)^{39}$ ou de dietilditiocarbamato de sódio $\left(\mathrm{C}_{5} \mathrm{H}_{10} \mathrm{NNaS}_{2}\right)$ com ácido L-ascórbico $\left(\mathrm{C}_{6} \mathrm{H}_{8} \mathrm{O}_{6}\right)$ em $\mathrm{pH}$ ajustado a $5,0 .{ }^{22,25,37,50,60}$ Antes da fase de redução e quelação da matéria orgânica, alguns pesquisadores preferem não utilizar $\mathrm{HCl}$, tendo em vista os potenciais riscos de dissolução da amostra com este ácido forte. Em vez disso, a superfície de carbonato da amostra pode ser tratada com dietilditiocarbamato de sódio e ácido ascórbico, em pH ajustado a 2,5, até alcançar equilíbrio em pH 5,6 (Tabela 2). ${ }^{22}$

A maioria das etapas de limpeza de amostras de coral envolve banho ultrassônico e lavagens com água deionizada, sob determinadas condições de temperatura e tempo. O tempo gasto e a temperatura dependem do procedimento usado pelo pesquisador. A limpeza ácida é geralmente rápida, enquanto a remoção da matéria orgânica leva de minutos até algumas horas (Tabela 2). O procedimento de Shen e Boyle $^{39}$ e, principalmente, algumas adaptações deste procedimento foram bastante empregadas. Entretanto, a complexidade e a duração do referido procedimento limitam a determinação de um grande número de amostras. Em estudo recente, ${ }^{59}$ foi proposto um procedimento simples para a descontaminação de amostras de corais, que gerou resultados bastante satisfatórios. Este procedimento envolve apenas cinco etapas de lavagem com ácido diluído $\left(\mathrm{HNO}_{3} 0,2 \mathrm{~mol} \mathrm{~L}{ }^{-1}\right)$.

Mesmo após a redução do número de etapas de limpeza, com soluções ácidas bastante diluídas, e uso do banho ultrassônico, é possível que a agitação, durante o processo de sonicação em meio ácido, remova não apenas elementos-traço da superfície da amostra (decorrentes da contaminação), como também aqueles que constituem o próprio esqueleto do coral. Este é um ponto que deve ser melhor investigado para que os resultados das análises químicas não representem concentrações subestimadas dos analitos na matriz carbonática.

Uma alternativa mais simples, que resultaria em uma diminuição do tempo gasto no preparo de amostras, seria o desenvolvimento de amostradores e/ou testemunhadores, de material altamente resistente, mas, ao mesmo tempo, que não introduzam contaminação durante o processo de amostragem. O desenvolvimento de tubos de carbeto, de tungstênio e/ou titânio, por exemplo, poderia ser uma alternativa.

Após os procedimentos de descontaminação, os esqueletos deverão ser acondicionados em recipientes previamente descontaminados para posterior secagem ou liofilização da amostra. Em seguida, a amostra deverá ser moída.
A etapa de moagem é muito importante para reduzir e padronizar a granulometria da amostra, garantindo a sua homogeneidade. Quando se usa o gral e o pistilo para macerar a amostra, existe uma grande dificuldade em se atingir tamanho de partículas homogêneo. Já o uso de moinho de bolas e/ou criogênico produz uma boa trituração da amostra, gerando partículas finas e relativamente homogêneas, de forma que, apesar de pouco utilizado, este é o procedimento mais recomendado.

A temperatura, durante o processo de moagem com moinho de bolas, não deverá exceder $40^{\circ} \mathrm{C}$, principalmente quando se pretende determinar elementos voláteis na amostra. Assim, vários ciclos de 2 min deverão ser empregados para que a temperatura não exceda o limite de $40{ }^{\circ} \mathrm{C} .{ }^{65} \mathrm{Um}$ problema associado ao uso do moinho criogênico e do moinho de bolas é a pequena capacidade do frasco de moagem, que restringe a moagem a apenas algumas miligramas de amostras por vez.

Após a moagem, a amostra é submetida à decomposição/ dissolução, geralmente, com o uso de ácidos fortes, para posterior determinação de elementos majoritários e minoritários. A Figura 2 mostra o fluxograma, modificado, das etapas que são rotineiramente utilizadas na literatura para o pré-tratamento de amostras de corais. Observa-se que a secagem da amostra em estufa foi o procedimento mais utilizado, entretanto, o uso do liofilizador é recomendado, visto que evita a contaminação da amostra.

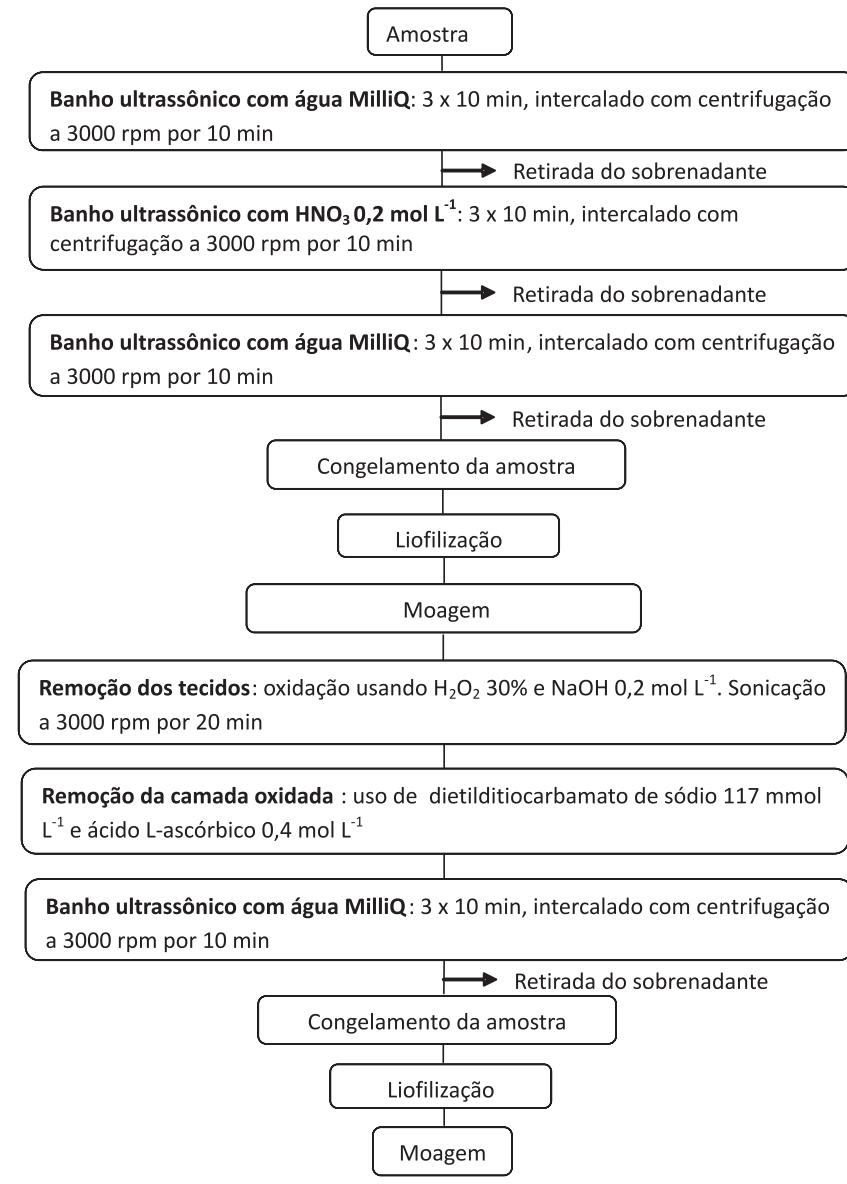

Figura 2. Fluxograma modificado das etapas de pré-tratamento de amostras de corais mais empregadas na literatura para a determinação de elementos majoritários e minoritários

Uma vez que as concentrações de elementos-traço são bastante baixas na matriz carbonática dos corais, as determinações são frequentemente realizadas por espectrometria de massa com plasma 
Tabela 2. Procedimentos de limpeza das amostras de esqueleto de coral

\begin{tabular}{|c|c|c|c|c|c|c|}
\hline Massa (g) & Reagente / concentração & Meio & $\mathrm{pH}$ & $\mathrm{T}\left({ }^{\circ} \mathrm{C}\right)$ & Tempo & Ref. \\
\hline \multirow[t]{8}{*}{-} & Água deionizada & Banho ultrassônico & & & & 31 \\
\hline & $\mathrm{HNO}_{3}$ conc. & - & & & $3 \mathrm{~s}$ & 55 \\
\hline & $\mathrm{HNO}_{3} 0,2 \mathrm{~mol} \mathrm{~L}^{-1}$ & Banho ultrassônico & & - & $10 \mathrm{~min}$ & 39 \\
\hline & $\mathrm{HNO}_{3} 0,15 \mathrm{~mol} \mathrm{~L}^{-1}$ & Banho ultrassônico & & - & $2 \min (5 x)$ & \\
\hline & \multicolumn{6}{|l|}{ Mistura de $50 \%-50 \%$ de $\mathrm{H}_{2} \mathrm{O}_{2} 30 \%$ e $\mathrm{NaOH} 0,2 \mathrm{~mol} \mathrm{~L}^{-1}$} \\
\hline & Mistura de Hidrazina $\left(\mathrm{H}_{2} \mathrm{NNH}_{2}\right)$ anidra $97 \%$; & Aquecimento; & & 80 & $30 \mathrm{~min}$ & \\
\hline & $\mathrm{NH}_{4} \mathrm{OH}$ conc.; & banho-maria; & & - & - & \\
\hline & $\mathrm{NH}_{4} \mathrm{OH} 7 \mathrm{~mol} \mathrm{~L}^{-1}$ & Agitação ultrassônica & & - & $2 \mathrm{~min}$ & \\
\hline \multicolumn{7}{|c|}{ Repetição dos itens 1 a 3 e depois, 1 e 2} \\
\hline- & $\mathrm{NaClO} 5 \%$ & & & & $24 \mathrm{~h}$ & 63 \\
\hline \multirow[t]{2}{*}{-} & Água MiliQ; & & & & & 61 \\
\hline & $\mathrm{H}_{2} \mathrm{O}_{2} 120$ vol. & & & & & \\
\hline \multirow[t]{3}{*}{ $\pm 1,5$} & $\mathrm{HNO}_{3} 0,2 \mathrm{~mol} \mathrm{~L}^{-1}$ & Banho ultrassônico & & & $5 \mathrm{~min}$ & 40 \\
\hline & $\mathrm{HNO}_{3} 0,15 \mathrm{~mol} \mathrm{~L}^{-1}$ & Banho ultrassônico & & & $5 \min$ & \\
\hline & $\mathrm{HNO}_{3} 0,15 \mathrm{~mol} \mathrm{~L}^{-1}$ & - & & & $4 \mathrm{~min}$ & \\
\hline- & $\mathrm{HNO}_{3}$ diluído & - & & & - & 67 \\
\hline \multirow[t]{5}{*}{-} & Água destilada; & Banho ultrassônico & & & $10 \mathrm{~min}$ & 36 \\
\hline & $\mathrm{HNO}_{3} 0,15 \mathrm{~mol} \mathrm{~L}^{-1}$ & - & & & $5 \mathrm{~min}$ & \\
\hline & Água destilada; & Banho ultrassônico & & & $10 \mathrm{~min}$ & \\
\hline & Mistura de $1: 1 \mathrm{de}_{2} \mathrm{O}_{2} 30 \%$ e $\mathrm{NaOH} 0,2 \mathrm{~mol} \mathrm{~L}^{-1}$ & - & & & $20 \mathrm{~min}$ & \\
\hline & $\mathrm{HNO}_{3} 0,15 \mathrm{~mol} \mathrm{~L}^{-1}$ & - & & & $5 \min$ & \\
\hline \multirow[t]{4}{*}{-} & Água MiliQ & Banho ultrassônico & - & - & - & 34 \\
\hline & $\mathrm{H}_{2} \mathrm{O}_{2} 9,7 \mathrm{~mol} \mathrm{~L}^{-1}$ e $\mathrm{NaOH}$ & - & 8,2 & 20 & $1 \mathrm{~h}$ & 50 \\
\hline & & Banho ultrassônico & - & - & $5 \mathrm{~min}$ & \\
\hline & $\begin{array}{l}\text { Dietilditiocarbamato de sódio }(2 \%, \mathrm{~m} / \mathrm{v}) / \\
\text { Ácido L-ascórbico }\left(70 \mathrm{~g} \mathrm{~L}^{-1}\right) \text {. }\end{array}$ & & 5,0 & 20 & $10 \min$ & \\
\hline \multirow[t]{4}{*}{$75-100$} & $50 \mathrm{~mL}$ de $\mathrm{H}_{2} \mathrm{O}_{2} 9,7 \mathrm{~mol} \mathrm{~L}^{-1}$ e $\mathrm{NaOH}$ & - & 8,2 & 20 & $1 \mathrm{~h}$ & 60 \\
\hline & & Banho ultrassônico & - & - & $10 \min$ & \\
\hline & $\begin{array}{l}50 \mathrm{~mL} \text { de: Dietilditiocarbamato de sódio }\left(117 \mathrm{mmol} \mathrm{L}^{-1}\right) / \\
\text { Ácido L-ascórbico }\left(0,4 \mathrm{~mol} \mathrm{~L}^{-1}\right)\end{array}$ & & 5,0 & 20 & $20 \min$ & \\
\hline & & Banho ultrassônico & - & - & $10 \min$ & \\
\hline \multirow[t]{4}{*}{$4,5 \pm 0,2$} & $5 \mathrm{~mL}$ de $\mathrm{H}_{2} \mathrm{O}_{2} 9,7 \mathrm{~mol} \mathrm{~L}^{-1}$ e $\mathrm{NaOH}$ & - & 8,2 & 20 & $1 \mathrm{~h}$ & 51 \\
\hline & & Banho ultrassônico & - & - & $10 \mathrm{~min}$ & \\
\hline & & Banho ultrassônico & - & - & $10 \mathrm{~min}$ & \\
\hline & & Banho aquecido & 8,2 & 20 & $1,5 \mathrm{~h}$ & \\
\hline$\approx 5$ & $\mathrm{HNO}_{3}$ baixa concentração & Banho ultrassônico & - & - & - & 56 \\
\hline- & $\mathrm{HNO}_{3}$ ultrapuro $0,1 \mathrm{~mol} \mathrm{~L}^{-1}$ & $\begin{array}{l}\text { Banho ultrassônico; } \\
\text { banho aquecido }\end{array}$ & - & $\begin{array}{c}- \\
50\end{array}$ & - & 57 \\
\hline $0,015-0,025$ & $\mathrm{HNO}_{3} 0,2 \mathrm{~mol} \mathrm{~L}^{-1}$ & Banho ultrassônico & & & & 58 \\
\hline- & $\mathrm{NaClO} 5 \%$ & & & & & 52 \\
\hline- & Água destilada & Sonicação & & & $4,5 \mathrm{~h}$ & 19 \\
\hline \multirow[t]{2}{*}{-} & $\mathrm{NaClO} 5 \%$ & & & & 5 dias & 64 \\
\hline & & Sonicação & & & $4 \mathrm{~h}$ & \\
\hline \multirow[t]{13}{*}{-} & $\mathrm{H}_{2} \mathrm{O}_{2} 9,7 \mathrm{~mol} \mathrm{~L}^{-1} ; \mathrm{NaOH}$ & - & 8,2 & 20 & Uma noite & 22 \\
\hline & & Banho ultrassônico & & & $10 \min$ & \\
\hline & & & - & 70 & $3,5 \mathrm{~h}$ & \\
\hline & $\mathrm{HCl}\left(1,2 \mathrm{~mol} \mathrm{~L}^{-1}\right)$ & - & - & - & $12 \mathrm{~h}$ & \\
\hline & $\begin{array}{c}\text { Dietilditiocarbamato de sódio }\left(117 \mathrm{mmol} \mathrm{L}^{-1}\right) \text { / Ácido L- } \\
\text { ascórbico }\left(0,4 \mathrm{~mol} \mathrm{~L}^{-1}\right)\end{array}$ & Agitação; centrifugação & - & - & 20 Min & \\
\hline & $\mathrm{HNO}_{3} 0,01 \mathrm{~mol} \mathrm{~L}^{-1}$ & & & & & \\
\hline & $\mathrm{H}_{2} \mathrm{O}_{2} 30 \% ; \mathrm{NaOH} 0,2 \mathrm{mo} \mathrm{L}^{-1}$ & & & & & \\
\hline & & Agitação ultrassônica e & & 60 & $2 \mathrm{~min}$ & \\
\hline & & centrifugação & & - & $10 \mathrm{~min}$ & \\
\hline & & Agitação ultrassônica e & & - & $10 \mathrm{~min}$ & \\
\hline & & centrifugação & & - & $5 \min$ & \\
\hline & $\mathrm{HCl} 1,2 \mathrm{~mol} \mathrm{~L}^{-1}$ & & & & & \\
\hline & $\mathrm{HNO}_{3} 0,02 \mathrm{~mol} \mathrm{~L}^{-1}$ & & & & & \\
\hline
\end{tabular}


Tabela 2. continuação

\begin{tabular}{|c|c|c|c|c|c|c|}
\hline Massa $(\mathrm{g})$ & Reagente / concentração & Meio & $\mathrm{pH}$ & $\mathrm{T}\left({ }^{\circ} \mathrm{C}\right)$ & Tempo & Ref. \\
\hline \multirow[t]{2}{*}{0,1} & Água deionizada & Agitação ultrassônica e & & & $10 \mathrm{~min}$ & 89 \\
\hline & & centrifugação & & & $5 \mathrm{~min}$ & \\
\hline \multirow[t]{2}{*}{0,1} & $\mathrm{HNO}_{3} 0,02 \mathrm{~mol} \mathrm{~L}^{-1}$ & $\begin{array}{l}\text { Agitação ultrassônica e } \\
\text { centrifugação }\end{array}$ & & & $\begin{array}{l}2 \min \\
2 \min \end{array}$ & 89 \\
\hline & $\mathrm{H}_{2} \mathrm{O}_{2} 30 \% ; \mathrm{NaOH} 0,2 \mathrm{~mol} \mathrm{~L}^{-1}$ & $\begin{array}{l}\text { Agitação ultrassônica e } \\
\text { centrifugação }\end{array}$ & & 60 & $\begin{array}{l}10 \mathrm{~min} \\
10 \mathrm{~min}\end{array}$ & \\
\hline- & $\mathrm{H}_{2} \mathrm{O}_{2} 9,7 \mathrm{~mol} \mathrm{~L}^{-1}$ e $\mathrm{NaOH}$ & - & 8,2 & 20 & $1 \mathrm{~h}$ & 25 \\
\hline \multirow[t]{4}{*}{0,025} & Água MiliQ; & Sonicação & & & & 91 \\
\hline & $\mathrm{NaOH} 0,2 \mathrm{~mol} \mathrm{~L}^{-1} 50: 50 \mathrm{H}_{2} \mathrm{O}_{2} 30 \%$ & & & & & \\
\hline & $\begin{array}{l}\text { Mistura de Hidrazina tamponada em mistura 50:50 de } \\
\mathrm{NH}_{4} \mathrm{OH} 30 \% \text { e }\left(\mathrm{NH}_{4}\right)_{2} \mathrm{C}_{6} \mathrm{H}_{6} \mathrm{O}_{7} 0,25 \mathrm{~mol} \mathrm{~L}^{-1} ;\end{array}$ & Aquecimento e sonicação & & & & \\
\hline & $\mathrm{HNO}_{3} 0,001 \mathrm{~mol} \mathrm{~L}^{-1}$ & & & & & \\
\hline $0,001-0,0015$ & Água MiliQ & $\begin{array}{l}\text { Agitação ultrassônica e } \\
\text { centrifugação }\end{array}$ & & & $10 \min (2 x)$ & 18 \\
\hline \multirow[t]{2}{*}{4,5} & & Banho ultrassônico & - & - & $10 \mathrm{~min}$ & \\
\hline & $\begin{array}{c}\text { Dietilditiocarbamato de sódio } 2 \%(\mathrm{~m} / \mathrm{v}) \text {; Ácido L-ascór- } \\
\text { bico }\left(70 \mathrm{~g} \mathrm{~L}^{-1}\right)\end{array}$ & & 5,0 & 20 & $10 \mathrm{~min}$ & \\
\hline- & $\mathrm{HNO}_{3} 0,2 \mathrm{~mol} \mathrm{~L}^{-1}$ & - & - & - & - & 21 \\
\hline- & Água MiliQ & Banho ultrassônico & & & & 90 \\
\hline \multirow[t]{6}{*}{4,5} & $\mathrm{H}_{2} \mathrm{O}_{2} 9,7 \mathrm{~mol} \mathrm{~L}^{-1} ; \mathrm{NaOH}$ & & 8,2 & 25 & $1 \mathrm{~h}$ & 37 \\
\hline & & Banho em água & 8,2 & 70 & $3,5 \mathrm{~h}$ & \\
\hline & Dietilditiocarbamato de sódio $20 \%(\mathrm{~m} / \mathrm{v})$ & & 5,0 & & & \\
\hline & $\mathrm{CaCl}_{2}\left(1-30 \mathrm{~g} \mathrm{~L}^{-1}\right)$ & & & & & \\
\hline & Ácido ascórbico $70 \mathrm{~g} \mathrm{~L}^{-1}$ & & & & $10 \mathrm{~min}$ & \\
\hline & (Repetição dos íntes 1 e 2) & Quente & & & $1,5 \mathrm{~h}$ & \\
\hline \multirow[t]{3}{*}{-} & $\mathrm{H}_{2} \mathrm{O}_{2} ; \mathrm{NaOH} 1 \mathrm{~mol} \mathrm{~L}^{-1}$ & & 8,2 & $\begin{array}{c}\text { Temp. } \\
\text { ambiente }\end{array}$ & $1 \mathrm{~h}$ & 44 \\
\hline & & Banho de água & & $70^{\circ} \mathrm{C}$ & $3 \mathrm{~h}$ & \\
\hline & & Banho ultrassônico $(2 \mathrm{x})$ & & & $10 \mathrm{~min}$ & \\
\hline- & $\mathrm{NaClO}$ & & & & $24 \mathrm{~h}$ & 10 \\
\hline
\end{tabular}

indutivamente acoplado (ICP-MS). Portanto, é conveniente que, na etapa de remoção dos tecidos, se utilize a mistura de $\mathrm{H}_{2} \mathrm{O}_{2}$ e $\mathrm{NaOH}$ como oxidante em vez de $\mathrm{NaClO}$, como sugerido em alguns trabalhos. ${ }^{10,52,63,64}$ Isto se justifica devido à interferência que o cloreto de hipoclorito pode causar nas determinações por ICP-MS.

\section{Decomposição de amostras de corais}

As amostras de corais, após as etapas de secagem, moagem e homogeneização, deverão ser submetidas à dissolução e/ou digestão para remover os analitos da matriz. Antes de realizar a extração dos analitos da matriz, é fundamental que seja feito um bom planejamento, o que envolve o conhecimento detalhado da técnica analítica a ser empregada, as características da matriz, o tipo do analito (inorgânico, orgânico), possíveis interferentes e outros problemas analíticos associados à técnica a ser empregada. ${ }^{66,67}$

Para a remoção dos elementos majoritários e minoritários da matriz carbonácea, em geral, as amostras são submetidas à decomposição com soluções ácidas. Existe uma grande variedade de extratores utilizados na literatura $\left(\mathrm{CH}_{3} \mathrm{COOH}, \mathrm{HNO}_{3}, \mathrm{HCl}\right.$ e $\left.\mathrm{HClO}_{4}\right)$, como pode ser observado na Tabela $3 .{ }^{15,37,50-52,63,68}$

Um grande número de estudos publicados sobre biomonitores não menciona o tipo de equipamento usado na decomposição das amostras, principalmente na literatura referente aos corais. Isto se deve, em parte, aos artigos de corais serem, principalmente, de cunho ambiental. Infelizmente, em muitos destes artigos, as informações sobre as condições experimentais são muitas vezes insuficientes para a reprodução do procedimento empregado.
Dentre a literatura avaliada, os equipamentos mais utilizados na decomposição de amostras de corais, bem como para outros organismos biomonitores, e.g. bivalves e poliquetas, estão o forno de micro-ondas, ${ }^{44,65,68-80}$ o bloco de aquecimento ou digestor ${ }^{19,31,55,81-84} \mathrm{e}$ a chapa quente (Tabela 3 ). ${ }^{85,86}$

$\mathrm{O}$ uso do forno de micro-ondas foi o procedimento para a digestão de amostras biológicas que se tornou mais popular nas últimas décadas. O seu emprego representou uma importante alternativa para os procedimentos convencionais, já que é relativamente barato, reduz o tempo de preparo de amostras e os problemas relacionados a perdas de elementos por volatilização. Além disso, entre as vantagens de se usar a radiação de micro-ondas na digestão, há a possibilidade de se trabalhar com ácidos diluídos e de controle da potência do forno, o que permite a redução do tempo de digestão. O tempo de digestão varia entre poucos minutos até $1 \mathrm{~h}$, o que é suficiente para assegurar a recuperação total dos elementos de interesse. ${ }^{87,88}$ Como as decomposições, geralmente, envolvem o uso de ácidos fortes é fundamental diluir as amostras após o seu resfriamento. A diluição evita a oxidação de partes metálicas de equipamentos onde serão determinados os analitos e o comprometimento da saúde do analista, que estará em contato com vapores fortes de ácidos.

\section{Determinação de elementos majoritários e minoritários em amostras de corais}

As técnicas analíticas utilizadas na determinação das concentrações de elementos majoritários e minoritários em amostras biológicas apresentam diferentes graus de sofisticação e seletividade, bem como 
Tabela 3. Digestão das amostras de esqueleto de coral e detecção de elementos majoritários e minoritários

\begin{tabular}{|c|c|c|c|c|c|}
\hline Massa (g) & Reagentes usados na decomposição & Equipamentos & Elementos & Técnica de detecção & Ref. \\
\hline- & $\mathrm{CH}_{3} \mathrm{COOH} 4 \%$ & Placa de aquecimento & $\begin{array}{l}\mathrm{Sr}, \mathrm{U}, \mathrm{Ba}, \mathrm{Cu}, \mathrm{B}, \mathrm{Li}, \mathrm{Zn}, \mathrm{Ti}, \mathrm{Cr} \\
\mathrm{Fe}, \mathrm{Mn}, \mathrm{Co}, \mathrm{Ni}, \mathrm{Pb}, \text { e SC }\end{array}$ & NAA e ICP OES & 31 \\
\hline $1-2$ & $\mathrm{HNO}_{3}$ & Placa de aquecimento & $\mathrm{Pb}$ & ASV & 55 \\
\hline \multirow[t]{3}{*}{$0,06-0,12$} & $\mathrm{HNO}_{3} 2 \mathrm{~mol} \mathrm{~L}^{-1}$ & - & $\mathrm{Ca}$ & FAAS & \multirow[t]{3}{*}{39} \\
\hline & $\mathrm{HNO}_{3} 16 \mathrm{~mol} \mathrm{~L}^{-1}$ & & $\mathrm{Co}$ & FAAS & \\
\hline & & & $\mathrm{Pb}, \mathrm{Cd}, \mathrm{Mn}, \mathrm{Zn}$ e V & GFAAS & \\
\hline- & $\mathrm{HCl} ; \mathrm{HNO}_{3}-\mathrm{HClO}_{4}(5: 1)$ & - & $\begin{array}{l}\text { As, V, Cr, Mn, Fe, Ni, Cu, Zn, } \\
\mathrm{Cd}, \mathrm{Pb}, \mathrm{Sn} \text { e BA }\end{array}$ & AAS & 63 \\
\hline- & $\mathrm{HNO}_{3}$ & - & $\mathrm{Cu}, \mathrm{Pb}, \mathrm{Zn}$ e $\mathrm{Cd}$ & ASV & 61 \\
\hline 0,12 & $\mathrm{HNO}_{3} 3 \mathrm{~mol} \mathrm{~L}^{-1}$ & - & $\mathrm{V}$ & ICP-MS & 40 \\
\hline- & $\mathrm{HCl}$ & - & $\begin{array}{l}\mathrm{Zn}, \mathrm{Cu}, \mathrm{Al}, \mathrm{Cr}, \mathrm{Cd}, \mathrm{Sn}, \mathrm{Pb}, \mathrm{V} \\
\text { e } \mathrm{Ni}\end{array}$ & AAS & 15 \\
\hline \multirow[t]{3}{*}{$0,05-1$} & $\mathrm{HNO}_{3}$ conc.; $\mathrm{HClO}_{4}$ diluído & - & $\mathrm{Cu}, \mathrm{Mn}, \mathrm{Ni}, \mathrm{Zn}, \mathrm{Fe}$ & INAA & \multirow[t]{3}{*}{67} \\
\hline & & & $\mathrm{Mg}, \mathrm{Al}, \mathrm{Cr}$ e $\mathrm{Co}$ & AAS & \\
\hline & & & $\mathrm{Ca}$ & $\begin{array}{l}\text { Complexometria usando } \\
\text { EDTA e indicador }\end{array}$ & \\
\hline \multirow[t]{2}{*}{$4,5 \pm 0,2$} & $\mathrm{HCl} 12 \mathrm{~mol} \mathrm{~L}^{-1}$ & & $\mathrm{Cd}, \mathrm{Pb}$ e $\mathrm{Cu}$ & ASV; & \multirow[t]{2}{*}{50,60} \\
\hline & & & $\mathrm{Zn}, \mathrm{Ni}$ e $\mathrm{Cr}$ & FAAS; & \\
\hline \multirow[t]{3}{*}{-} & $\mathrm{HNO}_{3} 1: 1 ; \mathrm{HCl}$ conc.; & & $\mathrm{Hg}$ & CV-AAS & \multirow[t]{3}{*}{36} \\
\hline & $\begin{array}{l}\mathrm{KMnO}_{4}(5 \%) ; \mathrm{HNO}_{3}(5,6 \mathrm{~mol} \mathrm{~L} \\
\mathrm{H}_{2} \mathrm{SO}_{4}(18 \mathrm{~N}) ; \text { Hidroxilamina }(1,5 \%) \\
\mathrm{SnCl}_{2}(10 \%)\end{array}$ & & & & \\
\hline & $\mathrm{HNO}_{3} 1: 1 ; \mathrm{HCl}$ conc.; $\mathrm{H}_{2} \mathrm{O}_{2} 36 \%$ & & $\begin{array}{l}\mathrm{Al}, \mathrm{Ca}, \mathrm{Cd}, \mathrm{Cu}, \mathrm{Cr}, \mathrm{Fe}, \mathrm{Pb}, \mathrm{V} \\
\text { e } \mathrm{Zn}\end{array}$ & ICP OES & \\
\hline- & - & - & $\mathrm{B}, \mathrm{Mg}, \mathrm{Ca}, \mathrm{Sr}$ e U & LA-ICP-MS & 34 \\
\hline \multirow[t]{2}{*}{$4,5 \pm 0,2$} & $\mathrm{HCl} 12 \mathrm{~mol} \mathrm{~L}^{-1}$ & $\begin{array}{l}\text { Digestão na temperatura } \\
\text { ambiente }\end{array}$ & $\mathrm{aCd}, \mathrm{Pb}$ e $\mathrm{Cu}$ & ASV; & \multirow[t]{2}{*}{51} \\
\hline & $\mathrm{LaCl}_{3} 0,18 \mathrm{~mol} \mathrm{~L}^{-1} ; \mathrm{HCl} 12 \mathrm{mmol} \mathrm{L}^{-1}$ & & $\mathrm{Zn}, \mathrm{Ni}$ e $\mathrm{Cr}$ & FAAS & \\
\hline \multirow[t]{2}{*}{$2-3$} & $\mathrm{HNO}_{3} 1: 1 ; \mathrm{HCl}$ & Banho-maria & $\mathrm{Hg}$ & $\begin{array}{l}\text { CVAAS-FI com cela de } \\
\text { quartzo e injeção em fluxo }\end{array}$ & \multirow[t]{2}{*}{56} \\
\hline & 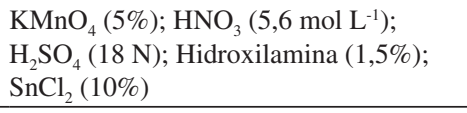 & & & & \\
\hline \multirow[t]{2}{*}{-} & $\mathrm{HNO}_{3}$ conc. ultrapuro; $\mathrm{HNO}_{3}(1 \%)$ & - & $\mathrm{Ca}$ & $\begin{array}{l}\text { Titulação com EDTA } \\
\text { (murexida como indicador); }\end{array}$ & \multirow[t]{2}{*}{57} \\
\hline & & - & $\mathrm{Pb}$ & $\begin{array}{l}\text { Quelação com pirrolidina } \\
\text { ditiocarbamato de amônio e } \\
\text { extração com metil isobutil } \\
\text { cetona }\end{array}$ & \\
\hline- & $\mathrm{HCl}$ & - & $\mathrm{Cd}, \mathrm{Cr}, \mathrm{Cu}, \mathrm{Fe}, \mathrm{Pb}, \mathrm{Sn}$ e $\mathrm{Zn}$ & AAS & \multirow[t]{3}{*}{52} \\
\hline \multirow[t]{3}{*}{-} & $\mathrm{HNO}_{3}$ e $\mathrm{HClO}_{4}(5: 1)$ & & & & \\
\hline & $\mathrm{HNO}_{3}: \mathrm{HCl}(9: 1)$ & & $\mathrm{Hg}$ & CVAAS & \\
\hline & $\begin{array}{l}\mathrm{HNO}_{3} \text { conc. e } \mathrm{H}_{2} \mathrm{O}_{2} \text { na proporção de } \\
1: 1 ; \mathrm{HCl}\end{array}$ & Placa de aquecimento & $\begin{array}{l}\mathrm{Al}, \mathrm{Fe}, \mathrm{As}, \mathrm{Br}, \mathrm{I}, \mathrm{Ba}, \mathrm{Mn}, \mathrm{Ni}, \\
\mathrm{Cu}, \mathrm{Zn}, \mathrm{Cd} \text { e } \mathrm{Pb}\end{array}$ & NAA / ICP-MS & 19 \\
\hline $0,015-0,025$ & $\mathrm{HCl} 5 \% ; \mathrm{HNO}_{3} 5 \%$ & - & $\mathrm{Cu}, \mathrm{Zn}$ e $\mathrm{Mn}$ & ICP OES & 58 \\
\hline \multirow[t]{2}{*}{$0,005-0,008$} & $\mathrm{HNO}_{3} 2 \%$ & - & $\mathrm{Sn}$ e $\mathrm{Cu}$ & ICP-MS & \multirow[t]{2}{*}{89} \\
\hline & & & $\mathrm{Ca}$ & ICP OES & \\
\hline $0,001-0,0015$ & $\mathrm{HNO}_{3} 1 \%$ & - & $\begin{array}{l}\mathrm{Na}, \mathrm{Mg}, \mathrm{Al}, \mathrm{Ca}, \mathrm{Mn}, \mathrm{Zn}, \mathrm{As}, \mathrm{Sr}, \\
\mathrm{Y}, \mathrm{Ag}, \mathrm{Cd}, \mathrm{Ba}, \mathrm{Pb}, \mathrm{Th} \text { e U }\end{array}$ & ICP-MS & 18 \\
\hline \multirow[t]{2}{*}{-} & $\mathrm{HCl} 12 \mathrm{~mol} \mathrm{~L}^{-1}$ & - & $\mathrm{Cu}$ & ASV & \multirow[t]{2}{*}{22} \\
\hline & & & $\mathrm{Sr}$ e Ca & FAAS & \\
\hline \multirow[t]{2}{*}{-} & $\mathrm{HNO}_{3} 1: 1$ & - & $\mathrm{Hg}$ & CVAAS & \multirow[t]{2}{*}{64} \\
\hline & $\mathrm{HNO}_{3}$ conc.; & & & & \\
\hline- & $\begin{array}{l}\mathrm{HCl} 2 \mathrm{~mol} \mathrm{~L}-1 \text { ultrapuro; } \mathrm{HCl} 2 \mathrm{~mol} \\
\mathrm{~L}^{-1} \text { enriquecida com padrão interno do } \\
\text { isótopo }{ }^{113} \mathrm{Cd} ; \mathrm{HNO}_{3} 2,5 \mathrm{~mol} \mathrm{~L}^{-1} ; \mathrm{HNO}_{3} \\
2 \%\end{array}$ & - & $\mathrm{Cd}$ & ID-ICP-MS & 91 \\
\hline
\end{tabular}


Tabela 3. continuação

\begin{tabular}{|c|c|c|c|c|c|}
\hline Massa $(\mathrm{g})$ & Reagentes usados na decomposição & Equipamentos & Elementos & Técnica de detecção & Ref. \\
\hline- & $\mathrm{HCl} 12 \mathrm{~mol} \mathrm{~L}^{-1}$ & - & $\begin{array}{l}\mathrm{Fe}, \mathrm{Zn}, \mathrm{Cu}, \mathrm{Co}, \mathrm{Cr}, \mathrm{Cd}, \mathrm{Mn}, \\
\mathrm{Pb} \text { e Ni}\end{array}$ & GFAAS & 25 \\
\hline \multirow[t]{2}{*}{-} & $\mathrm{HNO}_{3}$ conc. & Bloco digestor & $\mathrm{Cu}, \mathrm{Zn}$ e $\mathrm{Pb}$ & FAAS & 81 \\
\hline & & & $\mathrm{Cd}$ & ET-AAS & \\
\hline- & - & - & $\mathrm{Mn}, \mathrm{Fe}, \mathrm{Cu}, \mathrm{Cr}, \mathrm{Co}, \mathrm{Sb}, \mathrm{Pb}$ e As & LA-ICP-MS & 21 \\
\hline \multirow[t]{2}{*}{-} & $\mathrm{HNO}_{3}$ conc. & - & $\begin{array}{l}\mathrm{Cd}, \mathrm{Co}, \mathrm{Cr}, \mathrm{Cu}, \mathrm{Fe}, \mathrm{Mn}, \mathrm{Pb}, \mathrm{Ni} \\
\text { e } \mathrm{Zn}\end{array}$ & GFAAS & 37 \\
\hline & $\mathrm{LaCl}_{3} 0,18 \mathrm{~mol} \mathrm{~L}^{-1} ; \mathrm{HCl} 12 \mathrm{mmol} \mathrm{L}^{-1}$ & & & & \\
\hline 0,5 & $\mathrm{HNO}_{3} 30 \%$ & - & $\mathrm{Al}, \mathrm{Fe}$ e $\mathrm{Ca}$ & ICP OES & 90 \\
\hline \multirow[t]{2}{*}{1,0} & Água régia & & $\mathrm{Hg}$ & AFS & \\
\hline & $\begin{array}{l}\left.\mathrm{KMnO}_{4} 5 \%\right) \text {; hidroxilamina } 1,5 \% \text {; } \\
\mathrm{SnCl}_{2} 10 \%\end{array}$ & & & & \\
\hline- & - & Micro-ondas & $\begin{array}{l}\mathrm{Ca}, \mathrm{Sr}, \mathrm{Ba}, \mathrm{Mg}, \mathrm{V}, \mathrm{Ni}, \mathrm{Zn}, \mathrm{Al}, \\
\mathrm{Fe}, \mathrm{Cr}\end{array}$ & AAS & 44 \\
\hline 0,5 & $\mathrm{HCl} ; \mathrm{HNO}_{3}-\mathrm{HClO}_{4}(5: 1)$ & - & $\begin{array}{l}\mathrm{Fe}, \mathrm{As}, \mathrm{Cd}, \mathrm{Co}, \mathrm{Cr}, \mathrm{Cu}, \mathrm{Mn}, \mathrm{Ni}, \\
\mathrm{Pb} \text { e Zn }\end{array}$ & ICP-MS & 10 \\
\hline
\end{tabular}

AAS: Espectroscopia de Absorção Atômica; ASV: Voltametria de Redissolução Anódica; AFS: Espectroscopia de Florescência Atômica; CVAAS-FI: Injeção em Fluxo com Espectrometria de Absorção Atômica com Vapor Frio; CVAAS: Espectrometria de Absorção Atômica com Vapor Frio; ET-AAS: Espectroscopia de Absorção Atômica eletrotérmica; FAAS: Espectrometria de Absorção Atômica de Chama; GFAAS: Espectrometria de Absorção Atômica com Forno de Grafite; ICP OES: Espectrometria de Emissão Ótica com Plasma Indutivamente Acoplado; ICP-MS: Espectrometria de Massa com Plasma Indutivamente Acoplado; ID-ICP-MS: Diluição Isotópica com Espectrometria de Massa com Plasma Indutivamente Acoplado; LA-ICP-MS: Ablação a Laser com Espectrometria de Massa com Plasma Indutivamente Acoplado; NAA: Análise por Ativação Neutrônica; INAA: Análise Instrumental por Ativação Neutrônica.

de custos e tempo de análise. A escolha do método analítico a ser usado é baseada na faixa de concentração dos analitos de interesse, no custo analítico, no número de amostras e de elementos a serem determinados e, obviamente, na disponibilidade de equipamento.

Até a década de 1990, as técnicas utilizadas nas análises de traços em corais incluíam análise por ativação neutrônica (NAA), voltametria de redissolução anódica (ASV), sendo as técnicas espectrométricas de absorção atômica (AAS), com chama (FAAS) e com forno de grafite (GFAAS) as mais usadas. Posteriormente, a espectrometria de emissão e a espectrometria de massa, empregando fonte de plasma indutivamente acoplado (ICP OES e ICP-MS, respectivamente), começaram a ser muito utilizadas, haja vista a capacidade de determinação multielementar, a alta sensibilidade e os baixos limites de detecção.

O emprego das técnicas ICP-MS e ICP OES possibilitou a determinação simultânea de elementos-traço em estudos ambientais, para os quais existe a demanda de determinação da concentração de vários elementos tóxicos e essenciais, que na maioria das vezes se apresentam em concentrações muito baixas. Todos os métodos de análise química, mesmo os mais antigos, são usados ainda hoje, a depender do tipo de matriz, da faixa de concentrações do analito de interesse e da aplicação.

Para os estudos de corais publicados na literatura, uma gama de técnicas é utilizada (Tabela 3). Dentre as técnicas empregadas, destacam-se FAAS, GFAAS, CVAAS (para Hg), ICP OES e ICP-MS. $\mathrm{O}$ Hg é um elemento muito volátil em temperatura ambiente e por este motivo é determinado, geralmente, por espectrometria de absorção atômica com vapor frio (CVAAS) ou por fluorescência atômica (AFS).

A técnica analítica FAAS poderia ser utilizada, já que a instrumentação é relativamente simples e o custo moderado. Uma desvantagem desta técnica, no entanto, é a baixa eficiência do processo de introdução da amostra, pois apenas 5 a $10 \%$ da amostra chegam à chama. Isto pode significar um grande problema na determinação de traços em amostra biológica, caso as concentrações sejam muito baixas, como no caso de amostras de corais. Além disso, existe a possibilidade de problemas devido aos efeitos de matriz. Estes efeitos podem ser reduzidos pela adição de uma mistura de $\mathrm{LaCl}_{3} \mathrm{e} \mathrm{HCl}$ às $\operatorname{amostras}^{51}$ e o uso de lâmpada de lantânio e potássio no aparelho. ${ }^{22}$
Um dos grandes problemas relatados por pesquisadores, durante as determinações de elementos-traço em amostras ambientais complexas, como o esqueleto de coral e as conchas de organismos, é a elevada concentração de elementos majoritários como $\mathrm{Na}$ e Ca. A alta concentração destes elementos provoca interferência espectral e de transporte, perda de energia do plasma, reduzindo com isso o sinal analítico dos elementos-traço.

No caso de amostras biológicas coletadas em ambientes bem preservados, em que as concentrações de elementos são baixíssimas (i. e. ng L ${ }^{-1}$ ), é necessário utilizar GFAAS ou ICP-MS nas determinações químicas. Entretanto, dependendo do analito de interesse, existe uma diferença significativa, no limite de detecção do ICP-MS e do GFAAS, a qual pode chegar a duas ordens de magnitude. O GFAAS é uma técnica bastante sensível, indicada para a determinação de elementos ultratraço (da ordem de $\mu \mathrm{g} \mathrm{L}^{-1}$ ). A vantagem do GFAAS em relação ao ICP-MS está na possibilidade de analisar diretamente a amostra sólida ou volumes muito pequenos de amostras líquidas. No entanto, apesar de apresentar baixo limite de detecção, são comuns os problemas de interferência espectral (espalhamento de bandas eletrônicas) no GFAAS, exigindo um corretor de fundo muito eficiente, ${ }^{66}$ várias etapas no processo de aquecimento e limpeza, dificultando a viabilização da rotina de laboratório.

A espectrometria de emissão óptica com plasma indutivamente acoplado (ICP OES) e a espectrometria de massa com plasma indutivamente acoplado (ICP-MS) são as técnicas mais usadas para determinar simultaneamente a concentração de vários elementos-traço em esqueletos de corais. ${ }^{10,18,19,36,40,58,89,90}$

Na determinação de elementos-traço por ICP-MS, é necessário separar os metais alcalinos, que ocorrem em concentrações entre 500 e $1000 \mu \mathrm{L}^{-1}$, dos elementos-traço. Esta separação pode ser feita por meio da diluição isotópica e com o uso de uma resina de troca iônica. Este tipo de resina elimina os elementos majoritários, retendo os elementos minoritários. Posteriormente, os elementos-traço retidos são eluídos da resina, com o uso de uma solução ácida, sendo as concentrações determinadas por ICP-MS. ${ }^{91}$ No entanto, de acordo com Mathews e colaboradores ${ }^{91}$ e Scott, ${ }^{92}$ o uso da resina de troca iônica tem como desvantagem a possível perda de metais, durante a passagem destes na coluna de troca iônica. Outra forma de reduzir 
os efeitos de matriz do Ca analisado por ICP-MS é mediante o uso de padrões internos de escândio (Sc) e índio (In) nas soluções, antes da decomposição com o $\mathrm{HNO}_{3} 2 \%{ }^{89}$

Atualmente, as técnicas hifenadas vêm sendo cada vez mais usadas. A ablação a laser, acoplada ao ICP-MS (LA-ICP-MS), por exemplo, permite a determinação rápida e simultânea de elementos químicos em amostra sólida. O laser remove a camada superficial da amostra, a qual é injetada no espectrômetro de massa. A técnica LA-ICP-MS tem sido fortemente recomendada para a determinação de elementos majoritários e minoritários quando se necessita de alta frequência analítica. ${ }^{21,34}$ Porém, alguns problemas enfrentados para o uso de amostra sólida, usando LA-ICP-MS, são: a calibração exige o uso de soluções de calibração da mesma matriz, que ainda não são encontradas frequentemente e, as interferências espectrais, devido à matriz não ser diluída. Outra técnica utilizada é a diluição isotópica (ID) acoplada ao ICP-MS (ID-ICP-MS), pela qual é feita a adição de padrão do isótopo do analito na solução da amostra..$^{91}$

A escolha das técnicas analíticas para a determinação de traços muitas vezes é difícil e exige um amplo conhecimento da composição da matriz, visto todas as interferências que podem ocorrer. Amostras marinhas apresentam concentrações elevadas de elementos majoritários (e. g. sódio, magnésio, potássio, cálcio), o que pode causar sérias interferências no sinal analítico de elementos-traço. Alguns procedimentos podem ser feitos para minimizar estes efeitos. O excesso de água, bem como de sódio e cálcio presentes em amostras de corais, por exemplo, podem ser eliminados pela adição de solução de citrato de amônio $2 \%$ na matriz, antes da determinação das concentrações de elementos-traço. ${ }^{19}$

Todos os procedimentos mencionados acima devem ser realizados em capelas de fluxo laminar. O emprego de técnicas adequadas, reagentes e água de boa qualidade são fundamentais para a confiabilidade dos resultados. Para o controle de qualidade analítica, é fundamental a inclusão de amostras em branco e de material de referência certificado (MRC), nas determinações de elementos majoritários e minoritários. O MRC deverá ser usado para checar a precisão e a exatidão do procedimento e das análises químicas. Para os corais, geralmente, o MRC usado para amostras de corais é o JCP- 1, produzido pelo Geological Survey of Japan.

\section{CONCLUSÕES}

A capacidade de incorporação de elementos majoritários e minoritários em esqueletos de corais permite uma avaliação temporal das condicões do ambiente marinho (i. e. salinidade, temperatura e aporte de contaminantes no meio). As concentrações de elementos-traço variam substancialmente entre as espécies de corais. Isto resulta da interação de diversos fatores, como as fontes de contaminantes, teores de contaminação, biodisponibilidade de elementos majoritários e minoritários, fisiologia, tempo de vida e dieta de cada espécie. A utilização de corais como organismos biomonitores, entretanto, requer que sejam realizados procedimentos analíticos laboriosos e demorados, em salas limpas. O processamento de amostras de corais é complexo e envolve etapas de descontaminação antes da secagem, moagem e dissolução das amostras. É necessário o desenvolvimento de medidas alternativas para a amostragem de corais, que representa uma das etapas mais críticas, para que as etapas de descontaminação possam ser eliminadas e, assim, reduzir o tempo e a manipulação no pré-tratamento da amostra. As técnicas mais utilizadas nas análises de elementos-traço em amostras de corais são o AAS, o ICP-MS e o ICP OES, sendo estas últimas as mais empregadas, por serem técnicas multielementares, com alta sensibilidade, baixo limite de detecção e alta frequência analítica. É preciso enfatizar que os recifes de corais são ambientes que apresentam alta diversidade e produtividade primária, fornecendo uma série de serviços ecológicos que precisam ser preservados. Corais têm participação direta no balanço do carbono do planeta e, portanto, no clima do planeta, tanto devido aos processos de calcificação como de fotossíntese. Estes organismos são importantes ferramentas em estudos de monitoramento ambiental e precisam ser estudados e preservados.

\section{AGRADECIMENTOS}

Pelas bolsas de pesquisa do CNPq e pelos comentários e sugestões de dois revisores anônimos.

\section{REFERÊNCIAS}

1. Campbell, P. G. C.; Tessier, A. Em Ecotoxicology: a hierarchical treatment; Newman, M. C.; Jagoe, C. H., eds.; Editora Lewis Publishers: Cambridge, 1996, chap. 2.

2. Brezonik, P. L.; King, S. O.; Mach, C. E. Em Metal Ecotoxicology Concepts and Applications; Newman, M. C.; Mcintosh, A. W., eds.; Editora Lewis Publishers: Cambridge, 1991.

3. Duursma, E. K.; Carroll, J.; Environmental Compartiments. Equilibria and Assessment of Processes Between Air, Water, Sediments and Biota, Springer-Verlag: Michigan, 1996.

4. Luoma, S. N.; Rainbow, P. S.; Metal Contamination in Aquatic Environments: Science and Lateral Management, Cambridge University Press: New York, 2008.

5. Ng, T. Y. T.; Wang, W. X.; Mar. Ecol. Progr. 2004, 268, 161.

6. Sánchez-Marín, P.; Beiras, R.; Aquatic Living Resources 2008, $21,57$.

7. Monperrus, M.; Point, D.; Grall, J.; Chauvaud, L.; Amouroux, D.; Bareille, G.; Donarda, O.; J. Environ. Monit. 2005, 7, 693.

8. Rainbow, P. S.; Mar. Pollut. Bull. 1995, 31, 183.

9. Mitchelmore, C. L.; Verde, E. A.; Weis, V. M.; Aquat. Toxicol. 2007, 85, 48.

10. Kumar, S. K.; Chandrasekar, N.; Seralathan, P.; Bull. Environ. Contam. Toxicol. 2010, 84, 146.

11. Phillips, D. J. H.; Rainbow, P. S.; Biomonitoring of trace Aquatic Contaminants, $2^{\text {nd }}$ ed., Chapman and Hall: London, 1994.

12. Abilio, F. J. P.; Ruffo, T. L. M.; Souza, A. H. F. F.; Florentino, H. S.; Junior, E. T. O.; Meireles, B. N.; Santana, A. C. D.; Oecol. Bras. 2007, 11,397 .

13. Muscatine, L. Em Ecosystems of the World: Coral Reefs; Dubinsky, Z., ed.; Elsevier: Amsterdam, 1990.

14. Knutson, D. W.; Buddemeier, R. W.; Smith, S. V.; Science 1972, 177, 270.

15. Scott, P. J. B.; Davies, M.; Mar. Pollut. Bull. 1997, 34, 975.

16. Goreau, T. F.; Goreau, N. I.; Goreau, T. J.; Scientific American 1979, 124.

17. Wolf-Gladrow, D. A.; Zeebe, R. E.; Klaas, C.; Körtzinger, A.; Dickson, A. G.; Mar. Chem. 2007, 106, 287.

18. Ramos, A. A.; Inoue, Y.; Ohde, S.; Mar. Pollut. Bull. 2004, 48, 281.

19. Reichelt-Brushett, A. J.; Mcorist, G.; Mar. Pollut. Bull. 2003, 46, 1573.

20. Howard, L. S.; Brown, B. E. Em Oceanography and Marine Biology an Annual Review; Barnes, H.; Barnes, M., eds.; Aberdeen University Press: Aberdeen, 1984, vol. 22.

21. Edinger, E. N.; Azmy, K.; Diegor, W.; Siregar, P. R.; Mar. Pollut. Bull. 2008, 56, 1553.

22. Esslemont, G.; Russell, R. A.; Maher, W. A.; J. Mar. Syst. 2004, 52, 51.

23. Gattuso, J. P.; Allemand, D.; Frankignoulle, M.; American Zoologist 1999, 39, 160

24. Ferrier-Pagès, C.; Houlbrèque, F.; Wyse, E.; Richard, C.; Allemand, D.; Boisson, F.; Coral Reefs 2005, 24, 636.

25. Anu, G.; Kumar, N. C.; Jayalakshmi, K. V.; Nair, S. M.; Environ. Monit. Assess. 2007, 128, 195. 
26. Lavigne, M.; Field, M. P.; Anagnostou, E.; Grottoli, A. G.; Wellington, G. M.; Sherrell, R. M.; Geophys. Res. Lett. 2008, 35, 1.

27. Al-Rousan, S.; Al-Shaloul, R. N.; Al-Horani, F. A.; Abu-Hilal, A. H.; Mar. Pollut. Bull. 2007, 54, 1912.

28. Gagan, M. K.; Ayliffe, L. K.; Hopley, D.; Joseph, A. C.; Mortimer, G. E.; Chappell, J.; Mcculloch, M. T.; Head, M. J.; Science 1998, 279, 1014.

29. Carriquiry, J. D.; Villaescusa, J. A.; Clim. Past Discuss 2010, 6, 63.

30. Smith, S. V.; Buddemeier, R. W.; Redalje, R. C.; Houck, J. E.; Science 1979, 209, 404.

31. Livingston, H. D.; Thompson, G.; Limnol. Oceanogr. 1971, 16, 786.

32. Hanna, R. G.; Muir, G. L.; Environ. Monit. Assess. 1990, 14, 211.

33. Hart, S. R.; Cohen, A.; Geochim. Cosmochim. Acta 1996, 60, 3075.

34. Fallon, S. J.; Mcculloch, M. T.; Woesik, R. V.; Sinclair, D. J.; Earth Planet Sci. 1999, 172, 221.

35. Leão, Z. M. A. N.; Kikuchi, R. K. P.; Oliveira, M. D. M.; Biota Neotrópica 2008, $8,1$.

36. Bastidas, C.; García, E.; Mar. Pollut. Bull. 1999, 38, 899.

37. Jayaraju, N.; Reddy, B. C. S. R.; Reddy, K. R.; Soil and Sediment Contamination 2009, 18, 445.

38. Ali, A-H. A. M.; Hamed, M. A.; El-Azim, H. A.; Mar. Res. 2011, 65, 76.

39. Shen, G. T.; Boyle, E. A.; Chem. Geol. 1988, 67, 47.

40. Guzmán, H. M.; Jarvis, K. E.; Ambio. 1996, 25, 523.

41. Readman, J. W.; Tolosa, I.; Law, A. T.; Bartocci, J.; Azemard, S.; Hamilton, T.; Mee, L. D.; Wagener, A.; Le Tissier, M.; Robert, C.; Downing, N.; Price, A. R. G.; Mar. Pollut. Bull. 1996, 32, 437.

42. Sinclair, D. J.; Kinsley, L. P. J.; Mcculloch, M. T.; Geochim. Cosmochim. Acta 1998, 62, 1889.

43. Shen, G. T.; Boyle, E. A.; Earth Planet Sci. Lett. 1987, 82, 289.

44. Cram, S.; León, C. A. P.; Sommer, I.; Miceli, S.; Fernández, P.; Rivas, H.; Galicia, L.; Environ. Monit. Assess. 2009, 151, 413.

45. Reichelt-Brushett, A. J.; Harrison, P. L.; Mar. Pollut. Bull. 1999, 38, 182.

46. Reichelt-Brushett, A. J.; Harrison, P. L.; Coral Reefs 2005, $24,524$.

47. Kayser, H.; Mar. Biol. 1976, 36, 61.

48. Harland, A. D.; Brown, B. E.; Mar. Pollut. Bull. 1989, 20, 353.

49. Sabdono, A.; Res. J. Environ. Sci. 2009, 3, 96.

50. Esslemont, G.; Mar. Pollut. Bull. 1999, 38, 1051.

51. Esslemont, G.; Mar. Chem. 2000, 71, 215.

52. Khaled, A.; Nemr, E.; Sikaily, A. E.; Environ. Contam. Toxicol. 2003, $71,577$.

53. Dutra, L. X. C.; Haworth, R. J.; J. Sustainable development 2008, 1, 13.

54. Dutra, L. X. C.; Kikuchi, R. K. P.; Leão, Z. M.A.N.; Proceedings of the $10^{\text {th }}$ International Coral Reef Symposium 2006, 1090.

55. Dodge, R. R.; Gilbert, T. R.; Mar. Biol. 1984, 82, 9.

56. Guzmán, H. M.; García, E. M.; Mar. Pollut. Bull. 2002, 44, 1415.

57. Medina-Elizalde, M.; Gold-Bouchot, G.; Ceja-Moreno, V.; Mar. Pollut. Bull. 2002, 44, 421.

58. David, C. P.; Mar. Pollut. Bull. 2003, 46, 187.

59. Mendonça Filho, C. V. S. M.; dos Santos, W. P. C.; de Kikuchi, R. K. P.; Hatje, V.; Microchem. J. 2012, no prelo..

60. Esslemont, G.; Harriott, V. J.; Mcconchie, D. M.; Mar. Pollut. Bull. 2000, 40, 637

61. Mcconchie D.; Harriott, V. J.; Proceedings of the $7^{\text {th }}$ International Coral Reef Symposium, Guam 1992, 1, 97.

62. Gleyses, C.; Tellier, S.; Astruc, M.; Trends Anal. Chem. 2002, 21, 451.
63. Guzmán, H. M.; Giménez, C. E.; Mar. Pollut. Bull. 1992, 24, 554

64. Bastidas, C.; García, E. M.; Mar. Ecol. Progr. 2004, 267, 133.

65. Santos, W. P. C.; Hatje, V.; Lima, L. N.; Trignano, S. V.; Barros, F.; Castro, J. T.; Korn, M. G. A.; Microchem. J. 2008, 89, 123.

66. Levinson, R.; More modern chemical techniques, British Library: London, 2001.

67. Saunders, M. G.; Cabrera, M. R. M.; Peraza, E. F. H.; Insua, C.; Labrada, K. G.; Reyes, M. C. L.; J. Radioanal. Nucl. Chem. 1997, 219, 135.

68. Usero, J.; Morillo, J.; Gracia, I.; Chemosphere 2005, 59, 1175.

69. Manutsewee, N.; Aeungmaitrepirom, W.; Varanusupakul, P.; Imyim, A.; Food Chem. 2007, 101, 817.

70. Mubiana, K.; Blust, R.; Mar. Environ. Res. 2007, 63, 219.

71. Nesto, N.; Romano, S.; Moschino, V.; Mauri, M.; Ros, L. D.; Mar. Pollut. Bull. 2007, 55, 469.

72. Guimarães, V.; Sígolo, J. B.; Quim. Nova 2008, 31, 1696.

73. Sánchez-Marín, P.; Beiras, R.; Aquatic Living Resources 2008, 21, 57.

74. Affzah, N.; Vedamanikam, V. J.; Shazilli, N. A. M.; Toxicol. Environ. Chem. 2009, 91, 259.

75. Voets, J.; Redeker, E. S.; Blust, R.; Bervoets, L.; Aquat. Toxicol. 2009, 93, 53.

76. García-Rico, L.; Tejeda-Valenzuela, L.; Burgos-Hernández, A.; Bull. Environ. Contam. Toxicol. 2010, 85, 209.

77. Kucuksezgin, F.; Kacar, A.; Kucuksezgin, G.; Uluturhan, E.; Environ. Monit. Assess. 2010, 162, 407.

78. King, C. K.; Dowse, M. C.; Simpson, S. L.; Arch. Environ. Contam. Toxicol. 2010, 58, 657 .

79. Liu, J. H.; Kueh, C. S. W.; Mar. Pollut. Bull. 2005, 51, 857.

80. Osuna-Martínez, C. C.; Páez-Osuna, F.; Alonso-Rodríguez, R. A.; Bull. Environ. Contam. Toxicol. 2010, 85, 339.

81. Keller, N. B.; Demina, L. L.; Os'́kina, N. S.; Geochem. Int. 2007, 45, 832.

82. Bellotto, V. R.; Miekeley, N.; Anal. Bioanal. Chem. 2007, 389, 769.

83. Choi, H. J.; Ji, J.; Chung, K. H.; Ahn, I. Y.; Comp. Biochem. Physiol. 2007, 145, 227

84. Tapia, J.; Vargas-Chacoff, L.; Bertrán, C.; Carrasco, G.; Torres, F.; Pinto, R.; Urzúa, S.; Valderrama, A.; Letelier, L.; Food Chem. 2010, 121, 666.

85. Silva, E. G. P.; Hatje, V.; Santos, W. N. L.; Costa, L. M.; Nogueira, A. R. A.; Ferreira, S. L. C.; J. Food Composition and Analysis 2008, 21, 259.

86. Singh, R. K.; Chavan, S. L.; Sapkale, P. H.; Environ. Monit. Assess. 2007, 129, 471.

87. Arruda, M. A. Z.; Santelli, R. E.; Quim Nova 1997, 20, 638.

88. Trevizan, L. C.; Donati, G. L.; Nogueira, A. R. A.; Nóbrega, J. A. Em Trends in sample preparation; Arruda, M. A. Z., ed.; Nova Science Publishers, Inc.: Nova York, 2006.

89. Inoue, M.; Suzuki, A.; Nohara, M.; Kan, H.; Edward, A.; Kawahata, H.; Environ. Pollut. 2004, 129, 399.

90. Ramos, R.; Cipriani, R.; Guzman, H. M.; García, E.; Mar. Pollut. Bull. 2009, 58, 222.

91. Matthews, K. A.; Mcdonough, W. F.; Grottoli, A. G.; Technical Brief 2006, 7, 1 .

92. Scott, P. J. B.; J. Experimental Marine Biology and Ecology 1990, 139, 51. 